\title{
Different versions of the Easterlin Paradox: New evidence for European countries
}

Citation for published version (APA):

Kaiser, C. F., \& Vendrik, M. (2018). Different versions of the Easterlin Paradox: New evidence for European countries. Maastricht University, Graduate School of Business and Economics. GSBE Research Memoranda No. 026 https://doi.org/10.26481/umagsb.2018026

Document status and date:

Published: 13/12/2018

DOI:

10.26481/umagsb.2018026

Document Version:

Publisher's PDF, also known as Version of record

\section{Please check the document version of this publication:}

- A submitted manuscript is the version of the article upon submission and before peer-review. There can be important differences between the submitted version and the official published version of record.

People interested in the research are advised to contact the author for the final version of the publication, or visit the DOI to the publisher's website.

- The final author version and the galley proof are versions of the publication after peer review.

- The final published version features the final layout of the paper including the volume, issue and page numbers.

Link to publication

\footnotetext{
General rights rights.

- You may freely distribute the URL identifying the publication in the public portal. please follow below link for the End User Agreement:

www.umlib.nl/taverne-license

Take down policy

If you believe that this document breaches copyright please contact us at:

repository@maastrichtuniversity.nl

providing details and we will investigate your claim.
}

Copyright and moral rights for the publications made accessible in the public portal are retained by the authors and/or other copyright owners and it is a condition of accessing publications that users recognise and abide by the legal requirements associated with these

- Users may download and print one copy of any publication from the public portal for the purpose of private study or research.

- You may not further distribute the material or use it for any profit-making activity or commercial gain

If the publication is distributed under the terms of Article $25 \mathrm{fa}$ of the Dutch Copyright Act, indicated by the "Taverne" license above, 


\section{Maastricht University}

Caspar F. Kaiser,

Maarten C.M. Vendrik

Different Versions of the Easterlin Paradox: New Evidence for European Countries

RM/18/026

\section{GSBE}

Maastricht University School of Business and Economics

Graduate School of Business and Economics

P.O Box 616

NL- 6200 MD Maastricht

The Netherlands 


\title{
Different Versions of the Easterlin Paradox: New Evidence for European Countries*
}

\author{
Caspar F. Kaiser \\ Nuffield College, Oxford \\ Maarten C. M. Vendrik** \\ Maastricht University; ROA, Maastricht; IZA, Bonn; EHERO, Rotterdam
}

November 2018

\begin{abstract}
Richer people are happier than poorer people, but when a country becomes richer over time, its people do not become happier. This seemingly contradictory pair of findings of Richard Easterlin has become famous as the Easterlin Paradox. However, it was met with counterevidence. To shed more light on this controversy, we distinguish between five different versions of the paradox. These versions apply to either groups of countries or individual countries, and to either the long or the medium term. We argue that the long term is most appropriate for testing the paradox, and that tests of the paradox should always control for an autonomous time trend. Unfortunately, this requirement renders the long-term version of the paradox for individual countries untestable. We test all other versions of the paradox with Eurobarometer data from 27 European countries. We do so by estimating country-panel equations for mean life satisfaction that include trend and cyclical components of per capita GDP as regressors. When testing variants of the paradox that apply to groups of countries, we find a clear and robust confirmation of the long- and medium-term versions of the paradox for a group of nine Western and Northern European countries. Moreover, we obtain a non-robust rejection of the medium-term variant of the paradox for a set of eleven Eastern European countries. On the level of individual countries, the medium-term variant of the paradox clearly holds for the nine Western and Northern European countries, but is consistently rejected for Greece, Ireland, Italy, and Spain. In the case of the Eastern European countries, the medium-term version of the paradox is rejected for Bulgaria, Lithuania, and Poland. As the Western and Northern European countries have a high per capita GDP as compared to that of Southern and Eastern European countries, our results are in line with the finding of Proto and Rustichini (2013), who find a non-monotonic relation between per capita GDP and life satisfaction over time which is positive for poorer countries, but flat (or negative) for richer countries.

JEL codes: I31, I32, O11
\end{abstract}

Key words: Easterlin Paradox, happiness, life satisfaction, economic growth, Hodrick-Prescott filter, European country panel

* Acknowledgements: We thank Erik de Regt for econometric advice, Marta Golin for advice on using Stata, Guy Mayraz and Ruut Veenhoven for sending us their data sets, Daniel Sacks and Justin Wolfers for information about their research, and John Barkley Rosser Jr., Robert Dur, Richard Easterlin, Ari Kapteyn, Maurizio Pugno, Mariano Rojas, Francesco Sarracino, and other participants of the International Conference on Policies for Happiness and Health in Siena, March 19-21, 2018, the USC Happiness Conference at the occasion of the retirement of Richard Easterlin in Los Angeles, April 6, 2018, and the EHERO seminar in Rotterdam, October 24, 2018, for helpful comments.

** Corresponding author: Maarten Vendrik, Department of Economics, SBE, Maastricht University, P.O. Box 616, 6200 MD, Maastricht, The Netherlands. E-mail: m.vendrik@maastrichtuniversity.nl. Telephone: +31 (0)43 3624144. 


\section{Introduction}

It has been more than 40 years since Easterlin published his path-breaking study "Does economic growth improve the human lot: Some empirical evidence" (1974). In that and later papers (Easterlin, 1995, $2005,2017)$, he showed that while at a point in time individual happiness is positively correlated with individual income in the USA and other countries, over time average happiness in these countries does not trend upward as average income continues to grow. This seemingly contradictory pair of findings has become famous as the "Easterlin Paradox". Although these paradoxical findings have been confirmed for several other developed countries by other happiness researchers (e.g., Layard et al., 2010; Clark et al., 2014), there are also happiness scientists (e.g., Stevenson and Wolfers, 2008; Sacks et al., 2012, 2013; Veenhoven and Hagerty, 2006; Veenhoven, 2011; Veenhoven and Vergunst, 2014; Diener et al., 2013b) who have presented counterevidence to the Easterlin Paradox. While Easterlin (1995, $2005,2015,2017)$ has found consistently insignificant long-term correlations between average life satisfaction and GDP per capita over time for the world as a whole as well as for subsamples of developed, less developed, and transition (mainly ex-communist) countries, the latter authors find significant positive correlations between subjective well-being (SWB) and GDP per capita for the world as a whole, either using various country panel data sets separately or using them in a combined fashion. Although Easterlin (2017) has convincingly pointed out several shortcomings in the contestants' studies, this still raises the question as to who is right.

In this study we investigate this issue both on a conceptual level and by conducting our own estimations on country panel models that are similar to those of Layard et al. (2010) and Sacks et al. (2013), using updated life satisfaction data from the Eurobarometer surveys. On a conceptual level we show that in the debate on the Easterlin Paradox at least two distinct versions of this paradox are discussed. The first version (henceforth, EPi0, where i refers to individual countries) has been formulated above. The second version of the paradox extends the first part of the paradox to the positive correlation between average happiness and GDP per capita across countries (see, e.g., Deaton, 2008, Easterlin, 2017) and contrasts it with a zero cross-country correlation between (annual) rates of change in average happiness and GDP per capita over time. The latter correlation addresses the question of whether countries with a higher rate of economic growth exhibit a significantly more positive change in happiness. This seems like a mere cross-sectional reformulation of the second part of variant EPi0 of the paradox for groups of countries. However, there is an essential difference compared to time-series regressions that test whether individual countries with a positive rate of economic growth also experienced a positive time trend in happiness. In the cross-country regression, average annual rates of change in SWB are not only regressed on average annual rates of economic growth, but also on a constant (see, e.g., Easterlin, 2017, Table 1). This constant picks up drivers of (linear) trends in SWB other than economic growth that are common to all countries (e.g., trends in marriage and divorce rates, social capital, trust, aging, and income inequality; see Angeles, 2011; Bartolini and Sarracino, 2014, Bartolini et al., 2013a, 2013b; Gruen and Klasen, 2013). 
On the level of individual countries, this suggests that when a time-series regression of SWB of a specific country with positive economic growth reveals a significant positive time trend in SWB, this trend could be driven by trends in other determinants of SWB than economic growth (see also Clark, 2011, p. 259). In such a case the positive time trend in a country's SWB does not imply a non-spurious positive correlation between SWB and long-term economic growth in that country. Although, strictly speaking, the Easterlin Paradox only refers to the absence of positive bivariate correlations between SWB and long-term economic growth over time and does not address the issues of omitted variables and causality, a reliable test of the paradox should in our view at least control for possible spuriousness of a positive correlation between SWB and long-term economic growth that is driven by time trends in other determinants of SWB. Hence, to reliably test the Easterlin Paradox for individual countries, one should regress SWB in a country on the long-term economic growth trend while controlling for a country-specific autonomous time trend. Unfortunately, this is not possible due to perfect collinearity of such a time trend with the time-linear long-term economic growth trend. Thus, reliable tests of the Easterlin Paradox for separate individual countries do not seem possible.

However, there are two partial ways out of this problem. First, instead of controlling for a country-specific autonomous time trend, one may control for specific other determinants of SWB (see above) which do not develop exactly linearly in time, and hence are not perfectly collinear with the longterm economic growth trend. However, such an approach raises the thorny question which other determinants of SWB are predetermined with respect to per capita GDP, and hence should be controlled for ("good" controls in the terminology of Angrist and Pischke, 2009), and which determinants are mediating the effect of per capita GDP on SWB, and hence should not be included when wishing to estimate the total correlation of per capita GDP and SWB over time ("bad" controls). Moreover, the selected good control variables may not capture all autonomous determinants of SWB that vary in a linear-trend-like fashion. To circumvent these problems, one may adopt a country-panel approach to testing the Easterlin Paradox as introduced by Layard et al. (2010) and also used by Sacks et al. (2013). In this approach, which we follow in the present study, real GDP per capita (GDPpc) data are corrected for short-term business cycle effects ${ }^{1}$ by means of a Hodrick-Prescott (HP) filter (Hodrick and Prescott, 1997), and the resulting GDPpc trend and cyclical components are used as regressors in panel regressions for the average SWB in countries.

In this study we use two variants of the HP filter: The first one sets the parameter $\lambda$ of the HP filter to its conventional value 6.25 for annual data (see Ravn and Uhlig, 2002), which is also used by Sacks et al. (2013). ${ }^{2}$ This filters out fluctuations in GDPpc due to business cycles of up to about eight

\footnotetext{
${ }^{1}$ See the distinction between short-term fluctuations and long-term trends in GDPpc made by Easterlin (2017, Sect. 2).

${ }^{2}$ Layard et al. (2010) adopt a value of 9.5 for $\lambda$, but mention in their note of Table 6.5 that setting $\lambda=6.25$ produces similar results.
} 
years of length (as defined by Burns and Mitchell, 1946; see, for example, Fig. 1a for the Netherlands). ${ }^{3}$ The second HP filter that we use is a linear trend filter with $\lambda=\infty$ that filters out longer cycles in the GDpc data as well and that is close to the methodology used by Easterlin (2017) and Veenhoven and Vergunst (2014). This filter is the least-squares fit of a linear trend model for GDPpc with a slope coefficient given by the average growth rate of GDPpc over the whole estimation period (see Fig. 1b). This filter also corresponds to the average growth rate used as regressor in the SWB regressions of Easterlin (2017) and Veenhoven and Vergunst (2014) and filters out all cyclical fluctuations within the estimation period. In particular, in the case of the transition of ex-communist countries from communism to capitalism, the linear trend filter filters out contraction-expansion cycles, which may take up to 20 years, and hence last much longer than the usual business cycles. ${ }^{4}$ In this context, Easterlin (2017) makes the point that for allowing the average growth rate of GDPpc to filter out such transition cycles, the estimation period should be long enough, i.e. in the order of at least twenty years for transition countries. Generally, in order to test for a long-term correlation between SWB and GDPpc in countries over time as referred to in the Easterlin Paradox, the most appropriate filter of GDPpc is one that corrects for all cyclical fluctuations - no matter their duration. Such a filter is the linear trend filter of GDPpc with $\lambda=$ $\infty$, which thus seems more suitable for this purpose than HP filters of GDPpc with lower values of $\lambda$ as used by Layard et al. (2010) and Sacks et al. (2013).

\section{Insert Figure 1 here}

However, a limitation of the linear time trend filter for testing the Easterlin Paradox for separate individual countries as mentioned above, is that one can then not control for an autonomous time trend due to perfect collinearity of such a time trend with the filtered GDPpc series. In this respect, using a HP filter of GDPpc with $\lambda=6.25$ would work better, as such a filter generates a trend GDPpc variable with a (slowly) varying growth rate. Because of this variation, this trend GDPpc variable is not perfectly collinear with an autonomous time trend and can therefore be used for testing the absence of a correlation between SWB and GDPpc over time while controlling for an autonomous time trend. On the other hand, because a HP filter of GDPpc with $\lambda=6.25$ only corrects for business cycle fluctuations up to about eight years of length, and hence not for cyclical fluctuations of longer duration, we may better refer to tests of the Easterlin Paradox by means of such a filter as tests of a (stronger) medium-term version of the paradox. Thus, a further distinction between different versions of the Easterlin Paradox that we can draw is that between medium-term variants in terms of trend GDPpc with $\lambda=6.25$ (or values close to that) and genuine long-term variants in terms of the time-linear trend GDPpc with $\lambda=\infty$. The medium-

\footnotetext{
${ }^{3}$ Hamilton (2017) criticizes the HP filter for introducing spurious dynamic relations in the cyclical component that have no basis in the underlying data-generating process. However, for our purposes of regressing SWB on primarily an appropriate GDPpc trend measure, the HP filter seems more suitable than the alternative filter that is presented by Hamilton (2017). Moreover, this alternative filter generates similar results. See Section 5.2 for further discussion of this issue.

${ }^{4}$ In the usual classification of GDP cycles such transition cycles may be interpreted as a kind of Kuznets swings (Wikipedia, 2016).
} 
term trend GDPpc with $\lambda=6.25$ is itself fluctuating with wave lengths that tend to lie between roughly 15 and 30 years $^{5}$, and hence may be interpreted as those of a kind of Kuznets swing (see footnote 4 and Fig. 1b).

Finally, we can differentiate the Easterlin Paradox according to whether it is tested for individual countries separately or tested for groups of countries. In the former case, the growth rate of trend GDPpc only varies over time for a specific country, whereas in the latter case there is also (or solely) crosscountry variation in trend GDPpc growth rates that drives the overall correlation of trend GDPpc with SWB. Thus, combining all the distinctions made above, we can distinguish the following five variants of the Easterlin Paradox:

EPgl: Whereas at a point in time happiness varies positively with income both among and within countries, over time countries with a higher long-term rate of economic growth in a certain group of countries do not exhibit a more positive change in average happiness when controlling for a common time trend (Easterlin, 2017, p. 316; Veenhoven and Vergunst, 2014).

EPgm: Whereas at a point in time happiness varies positively with income both among and within countries, over time countries with a higher medium-term rate of economic growth in a certain group of countries do not exhibit a more positive change in average happiness when controlling for a common time trend (Layard et al., 2010; Sacks et al., 2013).

EPi0: Whereas at a point in time happiness varies positively with income within countries, over time average happiness in a particular individual country does not trend upward as average income trends upward (Easterlin, 1974). ${ }^{6}$

EPil (not testable!): Whereas at a point in time happiness varies positively with income within countries, over time a higher long-term rate of economic growth in a particular individual country is not associated with a more positive change in average happiness when controlling for a countryspecific time trend.

EPim: Whereas at a point in time happiness varies positively with income within countries, over time a higher medium-term rate of economic growth in a particular individual country is not associated with a more positive change in average happiness when controlling for a country-specific time trend.

We test these different versions of the Easterlin Paradox except the non-testable EPil for European countries by estimating country-panel equations for mean life satisfaction that include longor medium-term trend and cyclical components of GDPpc and country dummies as regressors. In doing

\footnotetext{
${ }^{5}$ For example, in the GDPpc data that we use we can identify cycles in medium-term trend GDPpc with wavelengths of up to about 23 years for West Germany and up to 30 years for the Netherlands (see Fig. 1b).

${ }^{6}$ We do not follow Easterlin $(2017$, p. 312) in extending the formulation of variant EPi0 to also include the variation of happiness with income across countries. This is because EPi0 only concerns the variation of happiness with income within countries. The same holds for the individual-country variants EPil and EPim below.
} 
so, we mostly take the first parts of the paradox' variants (i.e. correlations of happiness and income within and among countries) for granted because their validity has been confirmed in numerous empirical studies (e.g., Deaton, 2008; Sacks et al., 2012, 2013). In the case of testing the country-group variants EPgl and EPgm of the paradox by country-panel regressions, year dummies are controlled for as well and the error terms are clustered over countries to correct for heteroscedasticity and serial correlation. Furthermore, we distinguish various subgroups of countries to account for the heterogeneity in the correlations of mean life satisfaction and trend GDPpc between different country groups. More specifically, we partition our total sample of 27 countries into subsamples consisting of Western and Northern European, Southern European, and Eastern European countries. However, this leads to a downward bias in the cluster-robust standard errors due to the relatively low number of clusters or countries in these subsamples (and total sample; Cameron and Miller, 2015). Therefore, we also use an alternative estimation method which corrects for the serial correlation in the error term by adding oneyear-lagged mean life satisfaction to the regressors in the estimation equations. To correct for Nickell bias in the coefficient estimate for this variable, we use a bias-corrected least squares dummy variables estimator (Bruno, 2005). This extension of the estimation equation turns out to largely eliminate the serial correlation, and hence leads to reliable estimates of the correlation between mean life satisfaction and trend GDPpc for the various subgroups of countries.

To test the long-term variant EPi0 of the Easterlin Paradox for individual countries, we extend the approach of Easterlin (2017, p. 319) in estimating time trends of average happiness in individual countries by replacing the main effect term for trend GDPpc in our country-panel equations by the interaction of either a time trend or trend GDPpc with the country dummies and by replacing the main effect term for cyclical GDPpc by its interaction with the country dummies. Furthermore, instead of clustering the error term, we also add interactions of lagged mean life satisfaction with the country dummies so as to correct for country-specific serial correlation. Finally, the year dummies are replaced by dummies for different questions preceding the life satisfaction question in a restricted Eurobarometer data set. In a similar way, the medium-term variant EPim of the Easterlin Paradox is tested, but now interactions of both trend GDPpc and the time trend with the country dummies are included in the estimation equations. In this way, we can estimate country-specific correlations between mean life satisfaction and medium-term trend GDPpc while controlling for trends in other determinants of life satisfaction than economic growth.

The main results of these tests of the Easterlin Paradox are as follows. On the level of groups of countries, we find a clear and robust confirmation of the paradox for the long as well as medium term for a group of nine Western and Northern European countries. Moreover, we obtain a non-robust rejection of the paradox for the medium term for a set of eleven Eastern European countries. On the level of individual countries, the medium-term version of the paradox (EPim) clearly holds for the nine Western and Northern European countries, but is significantly rejected for Greece, Ireland, Italy, and Spain. Thus, in the latter four as opposed to the former nine countries, economic growth was positively associated with changes in life satisfaction in the medium term. In the case of the individual Eastern 
European countries, this also holds for Bulgaria, Lithuania, and Poland, but for the other EE countries results are unreliable, partially due to the limited length of the time series (only 11 years).

The remainder of this paper is organized as follows. Section 2 reviews the state of the debate on the Easterlin Paradox in the literature. In Section 3 the estimation equations for the tests of the different versions of the paradox are explained. Section 4 presents the data and descriptive statistics. Then, Sections 5 and 6 discuss the estimation results for groups of countries and individual countries, respectively, including various robustness estimations. Finally, Section 7 draws some general conclusions.

\section{State of the Debate}

Variant EPi0 (non-positive time trend in average happiness) of the Easterlin Paradox has been tested and confirmed by Easterlin $(1974,1995,2017)$ for the USA, by Easterlin $(1995,2005)$ and other happiness researchers (e.g., Layard et al., 2010, and Clark et al., 2014) for many other developed countries, and by Easterlin (2009) for several transition countries. On the other hand, Veenhoven (2011) has estimated trends in mean life satisfaction for fifteen developed countries over the period 1970-2010 and has found significant positive trends for seven out of these fifteen developed countries. As GDPpc trended upwards in the period considered in all the fifteen countries, Veenhoven's results imply a rejection of EPi0 for the seven developed countries with significant positive trends in life satisfaction. Similarly, Sacks et al. (2012) report that six out of nine European countries in the period 1973-1989 show a significantly positive regression relationship between average life satisfaction and $\ln (\mathrm{GDPpc})$ (see their Fig. 6). Because GDPpc trended upward in all the nine countries, these regressions may be interpreted as tests of EPi0, with the important limitation that these tests do not correct for businesscycle fluctuations in GDPpc. However, as argued above, in our view EPi0 is not an appropriate version of the Easterlin Paradox and should be replaced with the country-specific medium-term variant EPim of the paradox, as this controls for an autonomous time trend, and hence for a possible spurious correlation between the medium-term rate of economic growth and changes in happiness via a time trend in other determinants of happiness.

Most tests of the Easterlin Paradox in the literature are tests of EPgl and EPgm on the level of groups of countries. The long-term version EPgl has been tested using cross-country regressions of average rates of change in SWB on average growth rates of GDPpc by Easterlin, Veenhoven, and their co-workers. On the one hand, Easterlin and colleagues (see, e.g., Easterlin et al., 2010; Easterlin and Sawangfa, 2010; Easterlin, 2015, 2017) consistently find confirmations of EPgl for groups of developed countries, developing countries, transition countries, and all countries taken together. On the other hand, Veenhoven and Vergunst (2014) find a rejection of EPgl for a large combined data set of countries and attribute the differences of their results with those of Easterlin et al. (2010) to the comparatively much larger size of their data set. Furthermore, they find that the correlation between happiness and economic growth is quite strong in the 20 lower-income nations in their data set and relatively small in the high- 
income nations (Table 4b). However, Veenhoven and Vergunst's approach is extensively criticized by Easterlin (2017).

Layard et al. (2010) and Sacks et al. (2013) also test the Easterlin Paradox on the level of groups of countries using country-panel regressions. However, they test the time-series correlation of SWB with (less appropriate) medium-term rather than long-term trends in GDPpc because they use HP filters of GDPpc with $\lambda=9.5$ and 6.25, respectively. Employing Eurobarometer data for average life satisfaction in a group of 16 mainly Western European countries over the period 1973-2007, Layard et al. (2010) find insignificant coefficients of medium-term trend GDPpc in panel regressions of average life satisfaction while controlling for country-fixed effects, a time trend or year dummies, the cyclical GDPpc component, the unemployment rate, and the inflation rate. In our terminology, they thus test for and confirm EPgm for this group of Western European countries. However, the control for the unemployment rate may cause underestimation of the total effect of medium-term trend GDPpc, as parts of that effect may run via induced medium-term changes in the unemployment rate. Sacks et al. (2013), on the contrary, using several data sets for average SWB in groups of countries all over the world and estimating country-panel regressions of average SWB on medium-term trend GDPpc similar to those of Layard et al., find significant positive correlations of SWB and trend GDPpc for most of their data sets for the world as a whole in periods up to 2010. Moreover, when using Eurobarometer data for average life satisfaction (in a group of 30 European countries over the period 1973-2009), they find a significant positive correlation of SWB and trend GDPpc as well. However, they do not find significant correlations for their Gallup World Poll data set for a "ladder-of-life" version of SWB in a world-wide group of 141 countries in the period 2005-2011 and for Latinobarometro data for average life satisfaction in 18 Latin American countries in the period 2001-2010. Moreover, they do not report separate estimates for subsamples of Western and Eastern European countries, thus hampering a comparison of their results for European countries to those of Layard et al..

An interesting study by Proto and Rustichini (2013) moves the analysis forward by analysing the relation between GDPpc and life satisfaction without imposing a functional form on the term for GDPpc. They specify the variation of GDPpc in terms of quantiles and run micro-macro-panel regressions of life satisfaction data from the World Values Survey and Eurobarometer on the GDPpc quantiles while controlling for country and year-fixed effects, individual employment status, and personal income. These regressions reveal a non-monotonic relation between GDPpc and life satisfaction which is significantly positive for poorer countries and (European) regions, but becomes insignificant for richer countries and regions, and even turns significantly negative for the richest countries and regions. This suggests a rejection of the medium-term variant EPgm of the Easterlin Paradox for poorer countries and regions, but not necessarily of the more appropriate, long-term variant EPgl because the time series for the poorer countries and regions are too short for that. Another limitation of these tests is that the use of controls for individual employment status and personal income may either lead to an overestimation of the medium-term effects of GDPpc since effects of country-specific business cycles other than on individual employment status and personal income are not controlled for, 
or lead to an underestimation of the total medium-term effects of GDPpc since parts of that effect may run via induced medium-term changes in individual employment status and personal income. This ambiguity makes the use of these controls problematic. ${ }^{7}$

\section{Estimation Strategy}

In the present study we test all the above variants of the Easterlin Paradox except the untestable EPil with Eurobarometer data for average life satisfaction in 27 European countries over the period 19732015 , and compare our results to those from the literature discussed above. For that purpose, we conduct country-panel regressions which are similar to those of Layard et al. (2010) and Sacks et al. (2013), and extend them for testing EPi0 and EPim for individual European countries separately. In the sections below we present the life satisfaction equations we estimate.

\subsection{Estimation equations for testing the country-group variants of the Easterlin Paradox}

We begin with presenting the country-panel equations that we estimate to test the group variants EPgl and EPgm of the Easterlin Paradox. The baseline equation in this case has the form

$$
L S_{c t}=\beta \text { trend } \ln G D P p c_{c t}+\gamma \text { cyclical } \ln G D P p c_{c t}+\sum_{t \prime} \delta_{t} d_{t^{\prime}}+\sum_{c^{\prime}} \alpha_{c^{\prime}} d_{c^{\prime}}+\varepsilon_{c t}
$$

where $L S_{c t}$ is mean life satisfaction in country $c$ in year $t$, trend $\ln G D P p c_{c t}$ and $c y c l i c a l \ln G D P p c_{c t}$ are the long-term $(\lambda=\infty)$ or medium-term $(\lambda=6.25)$ trend and cyclical components of $\ln G D P p c_{c t}, d_{t}$, and $d_{c}$, represent year ${ }^{8}$ and country dummies, and $\varepsilon_{c t}$ is the error term. The year and country dummies account for, respectively, year-specific country-invariant determinants like differences in survey design across waves and common time trends and shocks, and country-specific time-invariant determinants like institutions and cultural differences in SWB scale use. The error term is clustered over countries to account for heteroscedasticity and serial correlation, which both occur in our estimations (Angrist and Pischke, 2009, Ch. 8).

We test the long- and medium-term versions of the paradox for a particular group of countries in two different ways: First, following the literature, we conduct two-tailed $t$ tests of a null hypothesis

\footnotetext{
${ }^{7}$ Beja (2014) and Opfinger (2016) also test for the Easterlin Paradox, but in our view the dynamic model of Beja on which he bases his tests is mis-specified (missing levels of lnGDPpc), and Opfinger only uses the last two waves of the WVS, which implies an estimation period of only five to seven years that is much too short to test the Easterlin Paradox in a reliable way. Furthermore, there is no control for country-specific business and longer cycle fluctuations.

${ }^{8}$ The Eurobarometer data set that we use for our measure of SWB, includes more than one survey wave per year in most cases. This allows us to exclude six waves in which the life satisfaction question has a different response scale (1-10) or is presented in a different way as compared to the other surveys. For the remaining waves, we take country-year averages of life satisfaction, and hence only control for year-fixed effects. This approach gives equal weights to different years of observations of average life satisfaction and is in line with the single observations per year of all the explanatory variables in our estimation equations. The alternative approach of taking country-wave averages of life satisfaction for each wave (as followed by Sacks et al., 2012, 2013) yields standard errors of the estimates which are very similar and only slightly smaller.
} 
of equality to zero of the parameter $\beta$ of trend $\ln G D P p c_{c t}$ for $\lambda=\infty$ and $\lambda=6.25$ against the alternative hypothesis of non-equality of $\beta$ to zero. If such tests fail to reject the null hypothesis or if the sign of $\beta$ is negative, EPgl (when $\lambda=\infty$ ) and/or EPgm (when $\lambda=6.25$ ) are confirmed. If the null hypothesis is rejected and the sign of $\beta$ is positive, EPgl, and/or EPgm are rejected. Alternatively, we conduct onetailed tests of the null hypothesis $\beta \leq 0$ against the alternative hypothesis $\beta>0$. If such tests fail to reject the null hypothesis, EPgl and/or EPgm are confirmed, whereas a rejection of the null hypothesis implies a rejection of EPgl and/or EPgm. As the p values in these one-tailed tests are half of those in the twotailed tests, EPgl and EPgm will more easily be rejected at conventional significance levels by the onetailed tests than by the two-tailed tests.

In the medium-term case, the estimate of parameter $\beta$ is driven by cross-country variation in trend GDPpc growth rates as well as variation in trend GDPpc growth rates in individual countries over time (see Fig. 1). However, in the long-term case the estimate of $\beta$ is merely driven by cross-country variation in the trend GDPpc growth rates, since trend GDPpc growth rates in individual countries are then constant over time (see Fig. 1b). The latter trend GDPpc growth rates correspond to the average long-term GDPpc growth rates that are used as regressor in regressions of average annual SWB changes in the methodology of Easterlin et al. and Veenhoven and Vergunst (2014). However, a difference with our approach in terms of country-panel regressions for mean SWB like (1) is that Easterlin et al. and Veenhoven and Vergunst (2014) follow a two-step procedure in which they first estimate long-term average rates of changes in mean SWB as well as GDPpc (in percentages) in the countries in the sample and then regress these average rates of change on each other, whereas we directly regress mean SWB levels in the countries on long-term trend lnGDPpc over time. A disadvantage of Easterlin's and Veenhoven and Vergunst's procedure in the case of samples with much less than ten SWB observations per country over time like the World Values Survey (WVS) is that then the estimated average rates of change in mean SWB tend to be unstable, i.e. sensitive to adding or dropping observations. According to a conventional rule of thumb in econometrics, stable estimates of regression coefficients require an amount of observations which is at least ten times the number of explanatory variables in the regression. Although the resulting measurement error in SWB trends may be random in large country samples, it may raise standard errors of the coefficients of the long-term GDPpc growth rate in the regressions for the long-term change in SWB, and therefore decrease the chances of rejecting EPgl. In the countrypanel approach of Layard et al (2010) and Sacks et al. (2013) that we follow, this complication is avoided by directly regressing SWB levels in countries on trend lnGDPpc over time with enough panel observations to get stable, and hence reliable, estimates of coefficient $\beta$ of trend $\ln G D P p c_{c t}$ in Equation (1).

A concern in our country-panel approach is that with a clustered error term, the asymptotic standard errors of the regression coefficients need to be corrected for the relatively low number of clusters, i.e. countries, in the sample and subsamples that we use (from 4 to 27; about 50 is the minimal required number of clusters, see Cameron and Miller, 2015, Section VI). Therefore, we employ the command regress $y x$, vce(cluster) in Stata, which includes a finite-sample adjustment of the cluster- 
robust standard errors and uses a $T$ distribution with $G-1$ degrees of freedom instead of a standard normal distribution for $t$-tests and $F$-tests based on these standard errors ( $G$ denotes the number of clusters). However, even with both adjustments, Wald tests generally tend to over-reject (op. cit.). In particular, in our tests of the Easterlin Paradox the remaining downward bias in the cluster-robust standard errors will lead to too high a likelihood of rejection of the null hypothesis for parameter $\beta$ (either $\mathrm{h}_{0}: \beta=0$ or $\left.\mathrm{h}_{0}: \beta \leq 0\right)$ of trend $\ln G D P p c_{c t}$ in Equation (1), and hence of the long and medium-term group variants EPgl and EPgm of the paradox. Therefore, we need an alternative, more reliable test. Such a test is provided by correcting for the first-order serial correlation over time more directly than by clustering standard errors over countries. Such correlation signals the joint effect on life satisfaction of lags of trend and cyclical lnGDPpc and lags of and serial correlation in time-varying omitted variables (see Vendrik, 2013, and Angrist and Pischke, 2009, Sect. 8.2.2), which implies that Equation (1) represents a dynamically incomplete model. Although testing the Easterlin Paradox does not require a complete dynamic model per se, the serial correlation, and hence the resulting downward bias in the standard errors of the parameter estimates, can be largely reduced by making Equation (1) dynamically more complete with the addition of one-year lagged mean life satisfaction to the right-hand side of eq.(1). ${ }^{9}$ This yields

$$
L S_{c t}=\beta \text { trend } \ln G D P p c_{c t}+\gamma \text { cyclical } \ln G D P p c_{c t}+\sum_{t^{\prime}} \delta_{t^{\prime}} d_{t^{\prime}}+\varphi L S_{c t-1}+\sum_{c^{\prime}} \alpha_{c^{\prime}} d_{c^{\prime}}+\varepsilon_{c t} .
$$

The lagged life satisfaction term picks up the joint effect of lags of trend and cyclical lnGDPpc and lags of and serial correlation in time-varying omitted variables. As the estimate of parameter $\varphi$ turns out to be significantly positive in our estimations, the initial effect ${ }^{10} \beta \Delta t r e n d \ln G D P p c_{c t}$ of a change in trend $\ln G D P p c_{c t}$ in year $t$ on life satisfaction is reinforced in year $t+1$ by $\varphi \beta \Delta$ trend $\ln G D P p c_{c t}$, in year $t+2$ by $\varphi^{2} \beta \Delta$ trend $\ln G D P p c_{c t}$ etc. In the end, this reinforcement process will converge to a total longrun effect $\frac{\beta}{1-\varphi} \Delta$ trend $\ln G D P p c_{c t}$ of the change in trend $\ln G D P p c_{c t}$ in year $t$ on life satisfaction (see Vendrik (2013) for a similar dynamics in a more complete dynamic life satisfaction model ${ }^{11}$ ). In this case the long and medium-term group variants EPgl and EPgm of the Easterlin Paradox for a particular group of countries are tested as a null-hypothesis of equality to zero or non-negativity of the long-run effect $\frac{\beta}{1-\varphi}$ of trend $\ln G D P p c_{c t}$ for $\lambda=\infty$ and $\lambda=6.25$, respectively.

\footnotetext{
${ }^{9}$ Because our regressors are likely not strictly exogenous, eliminating the serial correlation by a Prais-Winston or Cochrane-Orcutt transformation of the error term would not lead to consistent and efficient standard errors of the parameter estimates (Wooldridge, 2003, Sects. 12.3 and 12.5).

${ }^{10}$ We here use the term "effect" rather than "correlation" because a dynamic model like Equation (2) usually presupposes causality from the right-hand-side variables to the left-hand-side variable of the equation. Although testing of the Easterlin Paradox only involves correlations, dynamic-model concepts like short and long-run effects are more generally applicable to correlations as well.

${ }^{11}$ In that analysis adaptation of individual life satisfaction to income changes is modelled. In the simplified dynamics in the present paper such adaptation is implicitly and partially incorporated in the contemporaneous effects of the trend and cyclical lnGDPpc variables. See, however, the end of the next section for an extension that explicitly models adaptation of life satisfaction to medium-term changes in lnGDPpc.
} 
The dynamic-model concept of a long-run effect should be distinguished sharply from the concept of a long-term effect in the macro-economic time series context of the analysis of the Easterlin Paradox. Whereas $90 \%$ convergence to a long-run life satisfaction equilibrium usually takes place within a wide range of one to eleven years ${ }^{12}$, the expression "long term" refers to time periods of at least 20 years or so. A complication in the estimation of parameter $\varphi$ in the presence of country-fixed effects in Equation (2) is that it will suffer from a downward Nickell bias. To correct for this Nickell bias, we apply a bias-corrected least squares dummy variables (BCLSDV) estimator in Stata to correct for the Nickell bias in the coefficient of lagged life satisfaction (see Bruno, 2005, for the underlying econometrics). The command for this estimator calculates bootstrap standard errors of the parameter estimates of Equation (2), which are sufficiently reliable when the remaining serial correlation of the error term of Equation (2) turns out to be weak.

In line with Easterlin (2017), we apply two criteria for including countries in our tests of the Easterlin Paradox. First, to obtain a less heterogeneous sample in terms of population size, countries must have more than one million inhabitants. Second, the available surveys for average life satisfaction in a country should minimally span ten years and at least one complete cycle of GDPpc. ${ }^{13}$ Furthermore, we test the group variants EPgl and EPgm for the total selected group of countries as well as for several subgroups of Western and Eastern European countries separately (see Sect. 3). A concern regarding these tests is that their results may be driven by the Great Recession in the years 2008 to 2013. Therefore, as a robustness check, we also run regressions of Equations (1) and (2) for the years up to 2007. The medium-term estimates from these regressions for the subgroup of Western European countries are comparable with those of Layard et al. (2010) for this subgroup and the same period.

\subsection{Estimation equations for testing the individual-country variants of the Easterlin Paradox}

Apart from our above argument that variant EPi0 of the Easterlin Paradox is not an appropriate version of this paradox, a limitation in the estimation of time trends in average happiness in individual countries as conducted in the literature reviewed in the first paragraph of Section 2, is that these estimations do not control for differences in survey design across waves. In fact, it is not possible to obtain reliable estimates of time trends of average happiness in individual countries from separate regressions while controlling for wave or time-fixed effects because such fixed effects then pick up part of the time trend. A partial solution to this problem is offered by Easterlin (2017) on p. 319. He estimates time trends of average happiness in individual countries by adding interactions between country dummies and year to

\footnotetext{
12 The number of years $\tau$ within which convergence for $90 \%$ takes place can be calculated as $\varphi^{\tau}=1-0.9=0.1$ or $\tau \ln \varphi=\ln 0.1$ or $\tau=\ln 0.1 / \ln \varphi$. For a wide range of usual estimates of $\varphi$ between 0.1 and 0.8 this yields $1.0<\tau<$ 10.3 (cf. Vendrik, 2013).

${ }^{13}$ We do not use Easterlin's (2017) criterion of at least three available surveys for mean life satisfaction in a country as all countries in our Eurobarometer sample that satisfy the two criteria that we do apply, also have at least three available surveys in consecutive years. This is a sufficient condition for being able to estimate Equation (2) with control for lagged life satisfaction as well as country dummies (see above).
} 
a country-panel regression of average happiness on year while controlling for country-fixed effects as well as two dummies for specific changes in survey design. ${ }^{14}$ However, because he only uses these country-specific time trends in average happiness for regressing them on country-specific growth trends in GDPpc in groups of countries, he does not report significance levels of the time trends.

In this paper we extend this approach in several directions. We test variant EPi0 and mediumterm variant EPim of the Easterlin Paradox for individual countries separately in the following way. First, for testing EPi0 we replace in Equation (1) the main effect of trend $\ln G D P p c_{c t}$ for $\lambda=\infty$ by either its interactions with country dummies or the interactions of a time trend with the country dummies. Because of the perfect collinearity of the two sets of interactions, coefficient estimates for both sets can be considered as representing equivalent tests of the individual-country variant EPi0 of the Easterlin Paradox. In fact, the underlying assumption of testing EPi0 by estimating long-term time trends of mean happiness in individual countries is that these time trends represent the correlations of long-term trends in mean happiness with long-term economic growth trends of GDPpc. In this setting, (in)significance of the time trends implies (in)significant correlations of the development of mean happiness with longterm economic growth. However, the sizes of the country-specific interaction coefficients of year without control for trend GDPpc interactions are not identical to those of the corresponding interaction coefficients of trend $\ln G D P p c_{c^{\prime} t}$ without control for year interactions. The sizes of the latter coefficients more precisely represent the sizes of the (not-for-year-controlled) effects (or correlations) of the longterm economic growth trends on (with) the development of mean happiness in the individual countries. A remaining limitation of these estimates of the country-specific correlations of mean happiness with long-term economic growth is that they are not controlled for country-specific correlations of mean happiness with an autonomous time trend. To relieve this limitation we also conduct tests of the mediumterm variant of the Easterlin Paradox for individual countries (EPim). In this case, interactions of both trend GDPpc for $\lambda=6.25$ and the time trend with the country dummies can be included in the estimation equation. This allows estimating country-specific correlations between mean life satisfaction and medium-term trend GDPpc while controlling for trends in other determinants of life satisfaction than economic growth.

A third modification of Equation (1) is that in both tests of EPi0 as well as those of EPim and in deviation from the literature, we control for country-specific interactions (instead of main effects) of cyclical GDPpc with the country dummies. Our fourth change to Equation (1) is to drop the year-fixed effects because they would otherwise pick up part of the time trend for the reference country of the country dummies. A fifth modification is needed since asymptotic standard errors of the interaction coefficients implode with a clustered error term, as there is effectively only one cluster (country) for each country-specific coefficient estimate. We therefore control for the serial correlation in the error terms not by clustering them, but by adding interactions of one-year lagged life satisfaction (cf. Eq. (2))

\footnotetext{
${ }^{14}$ One dummy controls for two WVS surveys in which a question on financial satisfaction preceded the question on life satisfaction and the other dummy for three surveys with more extreme response options for the life satisfaction question.
} 
with the country dummies to Equation (1). Finally, to control for different preceding questions affecting responses to the life satisfaction equation, we select waves such that the number of distinct preceding questions across time is minimised and include dummies for the remaining different preceding questions in our estimation equations (see also footnote 8). Because the number of these dummies is still large (ten), insignificant dummies are dropped from the regressions (see Sect. 4 for more details on all these survey-design controls).

Implementing all these modifications results in an estimation equation of the form

$$
\begin{aligned}
L S_{c t}= & \sum_{c^{\prime}}\left[\beta_{c^{\prime}} d_{c^{\prime}} \text { trend } \ln G D P p c_{c^{\prime} t}+\gamma_{c^{\prime}} d_{c^{\prime}} \text { cyclical } \ln G D P p c_{c^{\prime} t}+\delta_{c^{\prime}} d_{c^{\prime}} \text { year }+\right. \\
& \left.\varphi_{c^{\prime}} d_{c^{\prime}} L S_{c^{\prime} t-1}+\alpha_{c^{\prime}} d_{c^{\prime}}\right]+\sum_{p} \delta_{p} d_{p}+\varepsilon_{c t},
\end{aligned}
$$

where $d_{p}$ represents the dummies for different preceding questions and where the interactions of the country dummies $d_{c^{\prime}}$ with either year or trend $\ln G D P p c_{c^{\prime} t}$ are dropped when testing EPi0. The interaction coefficients indicate country-specific short-run correlations of mean life satisfaction with trend $\ln G D P p c_{c^{\prime} t}$, cyclical $\ln G D P p c_{c^{\prime} t}$, year, and lagged mean life satisfaction, respectively. In an analogous way as for Equation (2), country-specific long-run correlations ${ }^{15}$ of mean life satisfaction with trend $\ln G D P p c_{c^{\prime}}$, cyclical $\ln G D P p c_{c^{\prime}}$, and year can be calculated as $\beta_{c^{\prime}} /\left(1-\varphi_{c^{\prime}}\right)$, $\gamma_{c^{\prime}} /\left(1-\varphi_{c^{\prime}}\right)$, and $\delta_{c^{\prime}} /\left(1-\varphi_{c^{\prime}}\right)$, respectively. Here we have no downward Nickell bias in the countryspecific estimates of $\varphi_{c^{\prime}}{ }^{16}$ as these estimates are only driven by the single cluster of observations for the specific country and Nickell bias only occurs with more than one cluster. Given the resulting implosion of clustered standard errors and when the remaining serial correlation in the error term of Equation (3) is weak, merely heteroscedasticity-robust or bootstrap standard errors can be used. Here we give preference to the type of standard errors which tend to be larger, as these seem to suffer less from downward finite-sample bias. For the bootstrap estimation of standard errors we chose to draw samples independently for each country (by means of Stata's strata option), as this seems to be the appropriate method for the interaction coefficient estimates and since sampling across all countries broke down.

However, a limitation in the estimation of these country-specific interaction coefficients is that the number of country-specific observations that drives the estimates of each of these coefficients is considerably lower than ten times the number of four interaction terms for each country in Equation (3) for EPim, i.e. 40, for many countries in our Eurobarometer data set. According to the econometric rule of thumb that we have mentioned in the previous section, this makes the estimates for these countries less reliable. Therefore, for countries with 30 to 40 observations we also conduct a robustness regression of Equation (3) in which the interaction term for cyclical $\ln G D P p c_{c^{\prime} t}$ has been replaced by its main effect term. Furthermore, for countries with 20 to 30 observations we run a robustness regression with the main effects instead of the interaction terms for both cyclical $\ln G D P p c_{c^{\prime} t}$ and $L S_{c^{\prime} t-1}$ in Equation

\footnotetext{
${ }^{15}$ See footnote 10 .

${ }^{16}$ This is revealed by equality of the estimates of $\varphi_{c^{\prime}}$ from regressions of Equation (3) without preceding question dummies to those from corresponding country-specific regressions for countries separately.
} 
(3). To correct for the Nickell bias in the non-country-specific coefficient of $L S_{c^{\prime} t-1}$ we again apply the bias-corrected least squares dummy variables (BCLSDV) estimator of Bruno (2005). However, now we do not use the bootstrap standard errors of the other coefficient estimates of Equation (3) from this estimator, but calculate bootstrap-with-strata standard errors in a regression of Equation (3) where the coefficient of $L S_{c^{\prime} t-1}$ has been fixated on the bias-corrected BCLSDV estimate. We follow this procedure because the required strata option for the interaction coefficient estimates (see above) is not available in the calculation of the bootstrap standard errors of the BCLSDV estimator. This specification is also our baseline for the Eastern European countries, where we only have 12 available observations per country. We then further run a robustness regression in which the interaction term for year has been replaced by its main effect. However, the latter regression is not very reliable as a test of the mediumterm variant EPim of the Easterlin Paradox for the Eastern European countries because country-specific correlations of mean life satisfaction with trend GDPpc are then only controlled for by a common time trend. Because of this concern, the much shorter time series, and the different levels and development of GDPpc of East as compared to Western European countries, we estimate the various variants of Equation (3) for subgroups of Western and Eastern European countries separately. Another worry regarding the tests of EPim as well as those of EPi0 for individual countries is that their results may be driven by the Great Recession in the years 2008 to 2013. Therefore, as a further robustness check of these tests for Western European countries ${ }^{17}$, we also run regressions of Equation (3) for the years up to and including 2007.

A final concern is that country-specific estimates of $\varphi_{c}$ and standard errors of all coefficient estimates are still biased for countries for which, after the addition of the interactions of one-year lagged life satisfaction, significant serial correlation in the error term continues to remain. To diminish this serial correlation, we add country-specific interactions of one-year lagged trend $\ln G D P p c_{c^{\prime} t-1}$ to the above variants of Equation (3) for the Western European countries in a further set of robustness checks. For countries for which the estimate of the interaction coefficient $\beta_{c^{\prime}}$ of trend $\ln G D P p c_{c \prime}$ is significant and positive and the estimate of the interaction coefficient $\beta_{-1 c^{\prime}}$ of trend $\ln G D P p c_{c^{\prime} t-1}$ is significant and negative, the latter coefficient estimate can be interpreted as modelling adaptation of life satisfaction to medium-term changes in GDPpc. For all countries, long-run correlations of mean life satisfaction with trend $\ln G D P p c_{c^{\prime}}$ are given by $\left(\beta_{c^{\prime}}+\beta_{-1 c^{\prime}}\right) /\left(1-\varphi_{c^{\prime}}\right){ }^{18}$

\section{Data and Descriptive Statistics}

For all estimations we use data from the nationally representative Eurobarometer surveys, ranging from 1973 to 2015 . To elicit responses on life satisfaction, respondents are typically asked the following

\footnotetext{
${ }^{17}$ For Eastern European countries the time series are too short to yield reliable robustness estimates for the years up to and including 2007 (only four years).

${ }^{18}$ This expression follows from noting that in the long-run equilibrium current and past values of all variables are equal to each other.
} 
question: "On the whole, are you very satisfied, fairly satisfied, not very satisfied or not at all satisfied with the life you lead?" with response options: "Very satisfied (1), fairly satisfied (2), not very satisfied (3), not at all satisfied (4)". In most years more than one EB survey took place. In order to obtain country-year averages of life satisfaction, we take the mean of all responses in a given year and country. ${ }^{19}$

For our estimations concerning groups of countries to test EPgl and Epgm (see Sect. 5), we include all waves apart from those in which the set of response options or question format deviate from the format given above. ${ }^{20}$ We exclude these waves because previous work has shown that such framing effects can have substantial effects on response patterns (Diener et al., 2013a). Henceforth, we will refer to this set of waves as "EB Standard". Since we cannot use year-fixed effects in our country-specific estimations that test EPi0 and EPim (see Sect. 3.2), it is even more crucial for our purposes that countryyear means of life satisfaction remain comparable over time. However, questions that immediately precede the life satisfaction question may impact answers to the life satisfaction question (see, e.g., Easterlin 2017). For our estimations in Section 6, we therefore select waves such that the number of distinct preceding questions across time is minimised, while continuing to have at least one EB wave available per year. This allows us to use dummies for these preceding questions without them being collinear with the time trend of the reference country. We will call this set of waves "EB Restricted". Table A.1 in Appendix A gives a list of the selected waves and the preceding questions for both "EB Standard" and "EB Restricted". In total, "EB Standard" and "EB Restricted" cover 35 countries for the years 1973 to 2015. Of these countries we exclude Cyprus, Luxembourg, and Malta because their populations do not exceed our threshold of one million inhabitants. We additionally exclude Albania, Iceland, Macedonia, Montenegro, Norway, and Serbia because they are observed for fewer than 10 years (see Sect. 3.1). This leaves us with 27 countries in total.

We use real and PPP-adjusted data on GDP per capita (GDPpc) for all estimations (in constant 2010 international \$). We primarily rely on data from the OECD (2017). Since not all European countries and years are covered by this data set, we supplement it with various other sources. In particular, we mainly use constant GDPpc data from the World Bank (2017) for Bulgaria, Croatia, and Romania. We also use this data for Ireland in 2015 because the OECD data for Ireland shows an implausible growth rate of $22 \%$ in that year. ${ }^{21}$ Furthermore, the OECD does not provide data on GDPpc for West and East Germany separately. For all years prior to 1991, we therefore use UNCTAD (2017) data for West Germany and data from Heske (2009) for East Germany. For years since 1991 we use data from the German Statistical Office (Destatis, 2017a). In cases where the OECD data does not extend

\footnotetext{
${ }^{19}$ We keep East and West Germany separate. To avoid any jumps in the series, we allocate the entirety of Berlin to East Germany for years after 1989. This is unlike the official coding in Eurobarometer, where the whole of Berlin is allocated to East Germany only from 2009 onwards (GESIS, 2017).

${ }^{20}$ These waves are: EB52.1, EB44.3OVR, EB62.2, EB63.1, EB72.1, and EB74.1.

${ }^{21}$ This extreme growth was largely driven by an accounting trick of a number of multinational companies (Inman, 2016). Therefore, this change in GDPpc is unlikely to have had an impact on living standards. The World Bank data set records a growth of only $7 \%$.
} 
far enough into the past, we use data from Penn World Tables (expenditure-side real GDP) (Feenstra, Inklaar, and Timmer, 2015). Finally, to minimize end-point problems in the estimation of the HodrickPrescott filter with $\lambda=6.25$, we use GDPpc projections by the IMF (2016) for the years 2016-2021. As this series is expressed in current prices, we convert this series into constant prices using the inflation projections from the IMF for these years.

Each of these series uses different base years and may differ in their exact computation. This is irrelevant across countries, given our use of the ln of GDPpc in combination with country-fixed effects. However, within countries we must correct for these differences. Therefore, in order to make the series we append to our reference series (which is typically the OECD series) comparable within countries over time, we apply the following formula:

$$
G D P p c_{c t}=\frac{G D P p c_{c s}^{\text {reference }}}{G D P p c_{c s}^{\text {append }}} * G D P p c_{c t}^{\text {append }}
$$

where $s=$ year of last (or first) observation of the reference series. For some robustness tests we further include the unemployment and the inflation rate to our estimations. We also primarily source this data from the OECD. Where there are gaps in these series, we supplement them with data from the World Bank. Moreover, in order to be able to have distinct series for East and West Germany, we use data from the Bundesagentur für Arbeit (2017) and DeStatis (2017b).

Tables 1 and 2 present descriptive statistics for each of the groups of Western and Eastern European countries. We distinguish between these groups primarily because of their very different levels of GDPpc, the fact that most Eastern European countries went through an economic transition from communism to capitalism after the collapse of the Soviet Union, and the much different observation windows we have available for each group. ${ }^{22}$ Mean levels of life satisfaction and GDPpc in the period 2004-2015 23 are clearly higher amongst Western than amongst Eastern European countries (3.07 vs. 2.68 and $\$ 38,017$ vs. $\$ 21,762$, respectively). However, the subset of Southern European countries (Spain, Greece, Italy, Portugal) falls short of that tendency and has a mean LS $(=2.61)$ and a mean GDPpc $(=\$ 30,386)$ closer to the Eastern European countries.

\section{Insert Tables 1 and 2 here}

To show how mean life satisfaction and mean GDPpc in the Western European countries have co-evolved over a long period, Figure A.1 in Appendix A presents graphs of these developments. This already suggests that for many of these countries there may be no significant long-term trend in life satisfaction (variant EPi0 of the Easterlin Paradox; see Sect. 1). ${ }^{24}$

\footnotetext{
${ }^{22}$ Mean $\mathrm{T}$ is 35 for the Western European countries and 13 for the Eastern European countries.

${ }^{23}$ This is the period for which life satisfaction data are available for all countries in our sample, allowing a reliable comparison of mean life satisfaction levels. The mean life satisfaction levels in Tables 1 and 2 refer to the "EBRestricted" set of waves, but are very similar to those for the larger "EB-Standard" (see above).

${ }^{24}$ We do not present analogous graphs for Eastern European countries since these are less interesting from a longterm perspective because of their short observation windows (13 years on average) and for reasons of space.
} 


\section{Results for Groups of Countries}

\subsection{Long-term variant of the Easterlin Paradox}

In this section we present the results of testing the long-term variant EPgl of the Easterlin Paradox for groups of countries. For this purpose, the life satisfaction data based on "EB Standard" was used (see Sect. 4). We begin with presenting the estimation results for Equation (1) (see Sect. 3.1). First, we estimate this equation for the group of all 27 European countries selected in Section 4. Figure 2a presents a scatterplot for this country group in which residuals from regressing Equation (1) for mean life satisfaction without trend $\operatorname{lnGDPpc}$ are plotted against residuals from regressing trend $\ln G D P p c_{c t}$ on the country and year dummies. The linear regression fit of this cloud of data points is rising, but only slightly and the slope as given by the coefficient estimate 0.10 of trend lnGDPpc in column (1) of Table 3, turns out to be strongly insignificant. However, a striking feature in the scatter diagram in Figure 2a is that the data points for Ireland (as indicated by red dots) are outliers with extremely low and high values of the residual of trend $\operatorname{lnGDPpc}$ (which represents the double difference of trend lnGDPpc with respect to its country and time means). This raises the question of what the impact of these outliers on significance and size of the slope of the regression line in Figure 2a is. This becomes visible in Figure $2 \mathrm{~b}$ where the data points for Ireland have been dropped from the regression. This leads to a remarkably strong rise in the slope of the regression line, which is reflected in a marginally $(p=0.10)$ significant $^{25}$ and much larger coefficient estimate of 0.62 for trend lnGDPpc in column (2) of Table 3 as compared to the estimate in column (1). The result of column (1) is hence largely driven by the outlier Ireland. Therefore, we drop Ireland from the subsequent regressions in this section.

Insert Figure 2 here

Insert Table 3 here

Thus, for our sample of 26 European countries without Ireland the long-term variant EPgl of the Easterlin Paradox is marginally rejected. However, Proto and Rustichini (2013) found a non-monotonic relation between GDPpc and life satisfaction, which is significantly positive for poorer countries and (European) regions, but insignificant or significantly negative for richer countries and regions. This suggests that our rejection of the paradox may be driven by the subgroup of the 13 less developed Eastern European countries with their lower mean GDPpc in our sample (see Sect. 4). Therefore, in column (3) we drop these countries from the regression, leaving us with 13 mainly Western European countries without Ireland (EU-13). For this EU-13 the coefficient estimate is insignificant, but surprisingly it is even somewhat larger in size than for the total group of 26 European countries without Ireland (0.78vs.

\footnotetext{
${ }^{25}$ In this study we call an estimate (strongly) significant when its p-value in a two-tailed t test is below $0.05(0.01)$, and marginally significant when its $\mathrm{p}$ value in a two- or one-tailed t test is higher than 0.05 , but lower than 0.10 . In the latter case we mention the $\mathrm{p}$ value in parentheses, which refers to a two-tailed t test unless it is explicitly stated that it refers to a one-tailed $t$ test.
} 
0.62). The large standard error (0.76) of this estimate may be due to a strong heterogeneity in the effects of differences in long-term economic growth on life satisfaction across different (groups of) EU-13 countries. Given the strong sensitiveness of mean life satisfaction in the Southern European (SE) countries Greece, Italy, Spain, and Portugal to the recent Euro crisis ${ }^{26}$ and their lower mean GDPpc (see Sect. 4), the large size of the coefficient for the EU-13 may be driven by this group of four SE countries. This is also suggested by the scatterplot for the EU-13 in Figure 3a in which the data points for the four SE countries are indicated by red dots. Dropping these data points from the regression, we obtain Figure $3 \mathrm{~b}$ with a slope that is virtually flat. This is reflected by the strongly insignificant and very small coefficient 0.01 of trend lnGDPpc in the regression for the nine remaining Western and Northern European countries in column (4) of Table 3. Thus, in this subgroup of highly developed countries (EU9) a higher long-term growth of GDP per capita was not associated with a more positive or less negative change in average life satisfaction in these countries. ${ }^{27}$ So, the group of these nine Western and Northern European countries clearly satisfies the long-term-variant EPgl of the Easterlin Paradox. ${ }^{28}$

\section{Insert Figure 3 here}

Figure 3 also suggests that when we restrict the regression to the four Southern European countries, the coefficient of trend lnGDPpc will be significant, positive, and large. However, column (5) of Table 3 shows that although this coefficient is indeed large and positive, it is not statistically significant $(\mathrm{p}=0.34)$. The large standard error that drives this $(=1.25)$ seems to be due to the coefficient of trend $\operatorname{lnGDPpc}$ being identified by only three ${ }^{29}$ differences in country-specific observations for the average growth rate of GDPpc. ${ }^{30}$ Finally, column (6) shows that for the group of 13 Eastern European (EE) countries the coefficient of trend lnGDPpc is marginally $(\mathrm{p}=0.06)$ significant, positive, and large.

\footnotetext{
${ }^{26}$ Graphs for individual countries like Figure 1 show that the recent Euro crisis is picked up by trend lnGDPpc for the medium term $(\lambda=6.25)$, and Figure A.1 strongly suggests that mean life satisfaction in the four SE countries was heavily affected by the Euro crisis (see also De Neve et al., 2018). This may be reflected in a high sensitiveness of mean life satisfaction in these countries to differences in long-term economic growth with other EU-13 countries.

${ }^{27}$ As Graham and Pestinato (2002) found no clear cross-country relationship between GDPpc and life satisfaction within a subsample of developed countries, we test whether there are significant positive correlations of (trend) lnGDPpc and life satisfaction across countries in the EU-9, as assumed in the first part of the variants EPgl and EPgm of the Easterlin Paradox (see Sect. 1). We average mean life satisfaction and mean (trend) lnGDPpc of the countries in the EU-9 over the period 1995-2015 for which there are data for all nine countries, and regress average life satisfaction on average (trend) GDPpc and a constant. This yields remarkable large and marginally significant coefficients of $\operatorname{lnGDPpc}(1.50)$ and trend $\operatorname{lnGDPpc}$ for $\lambda=\infty$ (1.50) and $\lambda=6.25$ (1.48), all with $\mathrm{p}=0.08$ in onetailed $t$ tests. In view of the small number of observations (nine), we take this as affirmative evidence for the first part of the Easterlin Paradox for the EU-9 group of countries.

${ }^{28}$ Interestingly, the coefficient of cyclical lnGDPpc is insignificant for this group of countries as well, so even cyclical fluctuations in GDPpc were not associated with changes in average life satisfaction in these countries.

${ }^{29}$ Given this extremely low number of effective observations, we also run a robustness regression of Equation (1) for this group of countries without cyclical lnGDPpc. This yields a coefficient of 1.66 with a standard error of 1.11 $(\mathrm{p}=0.23)$, which is close to marginally significant in a one-tailed $\mathrm{t}$ test.

${ }^{30}$ Note that in this case of $\lambda=\infty$, all usable variation for the estimation of $\beta$ in Equations (1) and (2) arises from cross-country variation in the average growth rate of GDPpc. This is in contrast to setting $\lambda$ to 6.25 as done in Section 5.2, where we are able to exploit both within and cross-country variation in the medium-term growth rate of GDPpc. For this reason it is to be expected for our estimated standard errors to be larger in this section.
} 
Thus, in this group of countries a higher long-term growth of GDP per capita was associated with a more positive change in average life satisfaction in these countries. This implies a marginal rejection of the long-term-variant EPgl of the Easterlin Paradox for this group of Eastern European countries (but see the end of this section for a qualification). Because these countries had a lower mean GDP per capita in the estimation period than the Western and Northern European countries (see Sect. 4), this is in line with the significantly positive relation between GDPpc and life satisfaction for poorer countries and European regions as found by Proto and Rustichini (2013).

However, especially the last result may be biased due to the small number (13) of country clusters. Clustered standard errors of the parameter estimates then tend to be underestimated (see Sect. 3.1). In our case this downward bias in the standard errors is likely to be especially strong as tests for first and second-order serial correlation of the error term (see Wooldridge, 2003, pp. 399-402) in Equation (1) show strong positive first-order serial correlation (in the order of $0.50-0.70$ ). ${ }^{31}$ We therefore reduce this first-order serial correlation by adding one-year lagged mean life satisfaction to the righthand side of Equation (1), yielding Equation (2). For comparison with the estimation results for Equation (1) in Table 3, Table 4 presents estimation results for Equation (2) for the same groups of countries as those distinguished in Table 3. In this case, the long-run effects of trend lnGDPpc and cyclical lnGDPpc are the relevant estimates that can be compared with the corresponding coefficient estimates in Table $3.32,33$

\section{Insert Table 4}

For the total sample of all 27 European countries, column (1) of Table 4 shows a strongly significant and large bias-corrected coefficient of 0.81 for lagged life satisfaction, which implies a strong persistence of mean life satisfaction. This persistence does not only reflect a possible direct reinforcing feedback from lagged to current life satisfaction, but also reinforcement of the effects of trend and cyclical GDPpc and all kinds of omitted variables (e.g., health) ${ }^{34}$ on life satisfaction. A serial correlation test for Equation (2) shows that, as a result of the addition of the lagged life satisfaction term, all firstorder and second-order serial correlation is eliminated (i.e. becomes insignificant) except for marginally $(p=0.08)$ significant, negative, and small (-0.05) first-order serial correlation for the EU-13 countries. Hence, the bootstrap standard errors of the parameter estimates calculated by the BCLSDV estimator in Stata (see Sect. 3.1) are more reliable than those obtained from the estimation of Equation (1). The

\footnotetext{
${ }^{31}$ The second-order serial correlation is significant for most groups, but relatively small (at most 0.16 ). We do not explicitly correct for that in the following.

32 In fact, in time-series analysis a static equation like Equation (1) is interpreted as the long-run-equilibrium equation that corresponds to a dynamic equation like Equation (2) (cf. Vendrik, 2013).

${ }^{33}$ Strictly speaking, we should adjust the linear time trend filter of lnGDPpc to the slightly shorter estimation period of Equation (2) as compared to Equation (1). However, as this only minimally changes the coefficient estimates for trend lnGDPpc in Table 4, we present the results for the unadjusted time trend filter.

${ }^{34}$ In Equation (2) such omitted variables work via changes in the error term which in the next year are reinforced via the lagged life satisfaction term. This reinforcement also picks up the effects of positive serial correlation in time-varying omitted variables. See Vendrik (2013) for a deeper dynamic analysis.
} 
coefficient estimates for trend lnGDPpc and cyclical lnGDPpc in column (1) of Table 4 can be interpreted as short-run effects of these variables (see footnote 10 in Sect. 3.1). The short-run effect of trend $\operatorname{lnGDPpc}$ is insignificant while that of cyclical lnGDPpc is significant. The reinforcement of these effects results in much larger long-run (LR) effects, which are nevertheless again insignificant for trend lnGDPpc and significant for cyclical lnGDPpc. A comparison of these long-run effects with the corresponding effects in column (1) of Table 3 shows that size and standard error of the long-run effect of trend lnGDPpc in Table 4 are both about twice as large as size and standard error of the effect in Table 3 whereas size and standard error of the long-run effect of cyclical lnGDPpc in Table 4 are similar and more than twice as large, respectively. In general, the much larger standard errors of the long-run effects in Table 4 do not only reflect the downward bias of the standard errors estimates in Table 3 due to the low number of clusters (13), but also the partial control for time-varying and serially correlated omitted variables via the added lagged life satisfaction term in Equation (2). Therefore, the estimates for Equation (2) in Table 4 seem more reliable than those for Equation (1) in Table 3.

For the sample of 26 European countries without Ireland, column (2) of Table 4 shows a longrun effect of trend lnGDPpc, which is again somewhat larger than the coefficient in column (2) of Table 3 , but which is now only marginally $(\mathrm{p}=0.06)$ significant in a one-tailed test. Hence, the marginal rejection of the long-term variant EPgl of the Easterlin Paradox for this group of countries in Table 3 is now ambiguous in Table 4. We also find such weak evidence for a rejection of EPgl for the group of 13 mainly Western European countries without Ireland (EU-13) in column (3) of Table 4 (one-tailed p = 0.08), which is in contrast with the insignificant result in Table 3 and which is due to the much larger size of the long-run effect of trend lnGDPpc. However, the long-run effect of cyclical lnGDPpc is now strongly insignificant. Furthermore, when we drop the four Southern European countries in column (4) of Table 4, the long-run effect of trend lnGDPpc is again strongly insignificant and even negative, implying a clear confirmation of the long-term variant EPgl of the Easterlin Paradox for this group of nine highly-developed Western and Northern-European countries (EU-9). ${ }^{35}$

For the group of four Southern European countries column (5) of Table 4 shows an insignificant long-run effect of trend lnGDPpc as well, which is consistent with the result in column (5) of Table 3. However, for the group of 13 Eastern European countries the strongly insignificant long-run effect of trend lnGDPpc in column (6) is inconsistent with the marginally significant effect of trend lnGDPpc in column (6) of Table 3. This is due to a much lower size as well as much larger standard error of the estimate in Table 4. Especially the much smaller size of the latter estimate is puzzling and may be driven by one or more outlier countries. Such outliers may be Turkey because it is not an ex-communist country like the other EE countries, and East Germany because it has been integrated with highly developed West Germany since 1990 and has a much longer time series for life satisfaction in our Eurobarometer

\footnotetext{
35 Thus, for this group of countries our affirmation of the Easterlin Paradox does not just rely on a "(...) failure to isolate statistically significant relationships between average levels of happiness and economic growth through time" (Stevenson \& Wolfers, 2008, p. 16), but rather is more firmly grounded in a negative (yet insignificant) relationship between the trend of GDPpc and average life satisfaction.
} 
dataset than the other EE countries (since 1990 vs. 2004). When we drop these two countries from the group of EE countries, the long-run effect of trend lnGDPpc as shown in column (7) of Table 4 becomes much larger and marginally significant in a one-tailed t test $(\mathrm{p}=0.07)$. In addition, an estimation of Equation (1) for the remaining subgroup of $11 \mathrm{EE}$ countries yields a significant coefficient (= long-run effect) of trend lnGDPpc (with size 0.568). We thus obtain weak evidence of a rejection of the longterm variant EPgl of the Easterlin Paradox for this group of 11 Eastern European countries (EE-11) (but see our qualification at the end of this section). Note that the long-run effect of cyclical lnGDPpc is significant as well for this EE-11.

Thus, our analysis has revealed a clear confirmation of the long-term variant EPgl of the Easterlin Paradox for the group of nine Western and Northern European countries except Ireland and a weak rejection for the group of eleven Eastern European countries except Turkey and East Germany. Furthermore, we did not find a significant rejection of EPgl for the group of four Southern European countries. This raises the question of how robust these results are to dropping or adding relevant control variables and to restricting the estimation period. This question is investigated in Table 5 where columns (1) to (3) refer to the group of nine Western and Northern European countries except Ireland (EU-9) and columns (4) to (6) refer to the other two groups. In column (1) cyclical lnGDPpc is dropped in Equation (2) as in Sacks et al. (2013) for the medium term. This has very little effect on the long-run effect of trend lnGDPpc, which remains strongly insignificant. In column (2) cyclical lnGDPpc is again included, but now, following Layard et al. (2010) (for the medium term), the unemployment rate (UR) and inflation rate (IR) in each country have been added as additional control variables. Surprisingly, the long-run effect of the unemployment rate is insignificant ${ }^{36}$ whereas the long-run effect of the inflation rate is strongly significant and negative. Upon the addition of these variables, the long-run effect of trend lnGDPpc remains strongly insignificant and becomes even considerably more negative than was the case in column (4) of table 4. Estimations that either control for only the unemployment rate or only the inflation rate suggest that this decline in the long-run effect of trend lnGDPpc is driven by the positive (insignificant) and mediating effect on life satisfaction of a stronger fall/weaker rise in the unemployment rate as well as the positive (significant) effect of a stronger fall/weaker rise in the inflation rate. To the extent that the latter fall in the inflation rate is not mediating the effect of a higher medium-term growth rate of GDPpc on life satisfaction ${ }^{37}$, the inflation rate should be controlled for (a "good" control in the sense of Angrist and Pischke (2009)), yielding a strongly insignificant estimate 0.423 of the (total) long-run effect of trend lnGDPpc. Column (3) investigates whether the insignificant long-run effect of trend lnGDPpc for this group of countries may be driven by the impact of the recent Great Recession by restricting the estimation period to the years before 2008. Again this has no impact on the strong insignificance of the long-run effect of trend lnGDPpc. Column (4) shows that this also holds for the group of Southern European countries.

\footnotetext{
${ }^{36}$ This seems due to multicollinearity of the unemployment rate with one or more other explanatory variables.

${ }^{37}$ For example, economic reforms in a country and globalization may lead to both higher long-term economic growth and lower inflation.
} 
Furthermore, column (5) presents the estimate of the long-run effect of trend lnGDPpc for Equation (2) without cyclical lnGDPpc for the group of eleven Eastern European countries without Turkey and East Germany (EE-11). In contrast with the estimate in column (7) of Table 4, this estimate of the long-run effect of trend lnGDPpc is now clearly insignificant despite an almost identical size due to a much larger standard error. Finally, column (6) shows that adding the unemployment rate and inflation rate to the regression of column (7) of Table 4 considerably diminishes the long-run effect of trend lnGDPpc and makes it even insignificant. Estimations that either control for only the unemployment rate or only the inflation rate suggest that this decline is driven by the positive long-run effect of a stronger fall/weaker rise in the inflation rate. ${ }^{38}$ In so far as a lower inflation rate is indeed not mediating the effect of a higher medium-term growth rate of GDPpc on life satisfaction ${ }^{37}$, this implies that the weak rejection of the long-term variant EPgl of the Easterlin Paradox for the EE-11 is not robust to controlling for the inflation rate (a "good" control). The positive long-run effect of a higher long-term growth rate of GDPpc in column (7) of Table 4 partially picks up the positive effect of a stronger fall/weaker rise in the inflation rate in column (6) of Table $5 !^{39}$

\section{Insert Table 5}

The estimations so far were based on the standard version of the Eurobarometer data for life satisfaction. However, in Section 6 for the individual countries, we will use a more restricted version of the Eurobarometer data for life satisfaction (see Sect. 4). Therefore, we also do robustness estimations of Equation (2) for this data set, one for the group of nine Western and Northern European countries without Ireland and one for the group of eleven Eastern European countries without Turkey and East Germany. This yields again strongly insignificant long-run effects of trend lnGDPpc and cyclical $\operatorname{lnGDPpc}$ for the former group and a marginally $(\mathrm{p}=0.06)$ significant long-run effect of trend lnGDPpc and a significant effect of cyclical lnGDPpc for the latter group (see Table B.1 in Appendix B). Finally, robustness estimations for the version of the Eurobarometer data for life satisfaction with all the waves in it, as in the EB datasets used by Layard et al. (2010) and Sacks et al. (2013), do not substantively change the results for the above two groups of countries either.

In sum, for the group of Northern and Western European countries (EU-9) we have obtained a clear and unambiguous affirmation of the long-term, and hence most appropriate, version of the Easterlin Paradox. Moreover, we have obtained weak and non-robust evidence for a rejection of EPgl for the set

\footnotetext{
${ }^{38}$ In the estimation where only the inflation rate is entered, the long-run effect of trend lnGDPpc is again insignificant for the EE-11 countries, while it becomes even somewhat larger and marginally significant in a onetailed test $(\mathrm{p}=0.07)$ when only controlling for the unemployment rate.

${ }^{39}$ We also did robustness regressions with the HP long-term trend in life satisfaction instead of life satisfaction as the regressand in Equation (1) for the long term while dropping the irrelevant cyclical lnGDPpc as regressor (we owe this suggestion to Francesco Sarracino). This more closely corresponds to the procedure of Easterlin (2017) and Veenhoven and Vergunst (2014) of regressing average rates of change in SWB on average growth rates of GDPpc across countries. This yielded coefficients of trend $\operatorname{lnGDPpc}$ with similar sizes and standard errors to those in Table 3. In this case the strong serial correlation in the error term cannot be corrected by adding the one-yearlagged long-term trend in life satisfaction to the regressors like in Equation (2) because of perfect collinearity of the one-year-lagged long-term trend with the long-term trend. See Section 6.1 for a related approach.
} 
of Eastern European countries without Turkey and East Germany. However, and this is our aforementioned qualification, in the latter case the estimation period is only 11 years (2004-2015), which includes short-term, but not medium-term cycles of GDPpc that tend to last between roughly 15 and 30 years (see Sect. 1). Hence, just as the HP filter for $\lambda=6.25$, the HP filter for $\lambda=\infty$ only filters out shortterm business-cycle fluctuations in the time series of GDPpc for these Eastern European countries. Thus, our tests of EPgl for this group of countries in effect only test the medium-term variant EPgm for the group of Eastern European countries without Turkey and East Germany. For a genuine test of the more appropriate, long-term variant EPgl for this country group longer time series are needed.

\subsection{Medium-term variant of the Easterlin Paradox}

We now turn to presenting results of our tests of the medium-term variant EPgm of the Easterlin Paradox for groups of countries. As explained in Sections 1 and 3.1, we do so by first computing our variables trend $\operatorname{lnGDPpc}$ and cyclical $\operatorname{lnGDPpc}$ by setting parameter $\lambda$ to 6.25 (instead of infinity) for the HP filter and then using these variables as regressors for estimating Equations (1) and (2). Our results from these regressions are most comparable to those of Layard et al. (2010) and Sacks et al. (2013) (see Sect. 2). In the main, our results for EPgm are similar to those for EPgl, but tend more towards rejecting the Easterlin Paradox. This makes sense as the HP filter for $\lambda=\infty$ filters out medium as well as short-term fluctuations in GDPpc whereas the filter for $\lambda=6.25$ only filters out short-term fluctuations (see Sect. 1).

As was the case in Section 5.1, scatter plots similar to those in Figure 2 again show that Ireland is an extreme outlier that drives our estimates of the coefficient of trend lnGDPpc in Equation (1) for the group of all 27 European countries downwards. However, contrary to our results for EPgl, the coefficient of trend lnGDPpc is now much larger (0.29) in column (1) of Table 6 and marginally significant in a one-tailed $t$ test $(p=0.07)$. Moreover, this coefficient becomes strongly significant in column (2) when excluding Ireland. Such more strongly significant effects are also observed when separating our sample into smaller groups of countries. Contrary to the insignificant coefficient of trend lnGDPpc for the set of 13 Western European countries without Ireland (EU-13) in Table 3 for the long term, we now find a strongly significant coefficient for this group of countries in Table 6 for the medium term. This is due to a much smaller standard error $(0.27 \mathrm{vs.} 0.76)$ rather than a much larger size $(0.86$ vs. 0.78) of the coefficient of trend lnGDPpc. The large size of this coefficient may again be driven by the group of Southern European (SE) countries. Indeed, when we drop this group from the regression, the coefficient of trend lnGDPpc for the remaining group of Northern and Western European countries (EU-9) becomes much smaller by a factor ten, and hence strongly insignificant. Thus, also for the medium term the Easterlin Paradox is clearly confirmed for the EU-9. Surprisingly, however, for the group of SE countries the coefficient of trend lnGDPpc is also smaller than for the EU-13 and insignificant. The large standard error of this estimate may be due to heterogeneity in the effect of changes in medium-term trend lnGDPpc on life satisfaction across these SE countries (see Sect. 6.2 for 
an explanation). Furthermore, and again in line with Section 5.1, we find a significant rejection of EPgm for the group of Eastern European countries. When excluding Turkey and East Germany (for reasons outlined in Sect. 5.1), the estimated coefficient increases somewhat (from 0.51 to 0.60 ), thus yielding a significant rejection of EPgm for this set of countries as well.

\section{Insert Table 6}

Unfortunately, we again find strong positive first-order serial correlation in the error terms of the regressions when estimating Equation (1) with our different subsamples. Given that this serial correlation causes a downward bias in our standard errors, we also conduct more conservative and reliable tests of EPgm using Equation (2). ${ }^{40}$ Our estimates of lagged life satisfaction are very similar to those in Table 4 and are hence not shown in Table 7. For the sake of brevity, Table 7 only presents the long-run effects of trend lnGDPpc and cyclical lnGDPpc. As may be expected, the level of statistical significance of the long-run effects of trend $\operatorname{lnGDPpc}$ in our present estimates of Equation (2) is always lower than was the case for Equation (1). Consequently, the clear rejection of EPgm shown in Table 6 for the group of EU-13 is now ambiguous in Table 7, where the long-run coefficient of trend lnGDPpc is only marginally $(p=0.06)$ significant in a one-tailed test. We further find a very clear confirmation of EPgm for the group of EU-9 countries with, just as in the long-term case, an even negative long-run effect of trend lnGDPpc. Finally, EPgm is confirmed for the group of all EE countries, but marginally $(p=0.10)$ rejected when we exclude Turkey and East-Germany from this group of countries.

\section{Insert Table 7}

We perform several robustness checks in a similar fashion as we did in Section 5.1. These checks can be found in Table B.2 in appendix B. Most of these results are broadly in line with those of Table $7 .^{41}$ For the group of Eastern European countries without Turkey and East Germany, the long-run effect of trend lnGDPpc again drops in size, and hence turns insignificant even for one-tailed tests, when adding unemployment and inflation rates to the set of controls. Similarly to the long-term case in column (6) of Table 5, this can be shown to be mainly driven by the positive long-run effect of a lower inflation rate. Again, when this lower inflation rate is not mediating the effect of higher long-term economic growth on life satisfaction (cf. footnote 37), this implies that the weak rejection of the medium-term

\footnotetext{
${ }^{40}$ Now all first and second-order serial correlation in the errors is eliminated when estimating Equation (2).

${ }^{41}$ To more closely compare our results with those of Layard et al. (2010), we also estimated Equation (2) for the total group of Western European countries including the Southern European countries for the period before 2008, adding the unemployment rate and inflation rate, while subsequently including and excluding Ireland. In both estimations, this yielded an insignificant long-run effect of trend lnGDPpc which is insensitive to including or excluding Ireland and is consistent with the results of Layard et al. (2010). However, in deviation from their results, the long-run effects of the unemployment rate and inflation rate are insignificant as well. This seems due to correlations of these variables with lagged life satisfaction, which is lacking in the regressions of Layard et al. (2010).
} 
variant EPgm of the Easterlin Paradox for the group of eleven Eastern European countries without Turkey and East Germany in Table 7 is again not robust to controlling for the inflation rate.

Hamilton (2017) criticizes the HP filter for introducing spurious dynamic relations in the cyclical component that have no basis in the underlying data-generating process. As an alternative to the HP trend component of a non-stationary I(1) or trend-stationary variable ${ }^{42}$ for $\lambda=6.25$, he proposes a predictor of the current value of the variable from its value two (and more) years earlier. However, replacing trend lnGDPpc and cyclical lnGDPpc in the regressions of Tables 6, 7, and B.2 by the alternative components proposed by Hamilton yields similar results to those in these tables. Therefore and because of the intuitive appeal of the smoothing procedure in the HP filter for the medium as well as long term, we stick to this filter in the present paper. ${ }^{43}$

In sum, our results for EPgm are similar to those for EPgl, but tend more towards rejecting the Easterlin Paradox. Nevertheless, one firm conclusion can be drawn: for the group of Northern and Western European countries (EU-9) we have obtained a clear and unambiguous affirmation of the Easterlin Paradox when framed in terms of its medium-term as well as long-term variant. Moreover, we have found non-robust evidence for a rejection of the Paradox for the medium term for the set of Eastern European countries without Turkey and East Germany (see the remark at the end of the previous section).

\section{Results for Individual Countries}

\subsection{Long-term variant of the Easterlin Paradox}

This section and the next present the results of testing the long- and medium-term variants EPi0 and EPim, respectively, of the Easterlin Paradox for individual countries. For this purpose, the restricted version of the Eurobarometer data for life satisfaction is used (see Sect. 4). As serial correlation tests show (marginally) significant and strong serial correlation in the error term of Equation (3) without interaction terms for lagged life satisfaction for most countries, we add these interaction terms to the regression equation. This eliminates the serial correlation for most countries, and hence we use bootstrap-strata standard errors. These standard errors turn out to be somewhat larger than heteroscedasticity-robust standard errors, which suggests that the bootstrap-strata standard errors suffer less from finite-sample bias than the heteroscedasticity-robust standard errors. Therefore, we present

\footnotetext{
${ }^{42}$ Augmented Dickey Fuller test show that lnGDPpc is non-stationary and I(1) for all EU-13 countries except West Germany and for Hungary, and trend-stationary for all other EE countries and West Germany in our sample.

${ }^{43} \mathrm{We}$ also did robustness regressions with the HP medium-term trend in life satisfaction instead of life satisfaction as the regressand in Equations (1) and (2) for the medium term while dropping the irrelevant cyclical $\operatorname{lnGDPpc}$ as regressor. However, trend life satisfaction turned out to be stationary only for the EU-9, and non-stationary and I(1) for all other groups of countries. For the EU-9 the estimates of the (long-run) effect of trend lnGDPpc were similar to those in Tables 3 and 4. For the other groups of countries the first difference of trend life satisfaction had to be regressed on the first difference of trend lnGDPpc. When controlling for the lagged difference of trend life satisfaction, this yielded implausibly small and insignificant long-run effects of the yearly change in trend lnGDPpc, which in view of the critical example of Hamilton (2017) on p. 8 are likely to be spurious.
} 
only bootstrap-strata standard errors in all tables with estimates for individual countries in this and the next section. We estimate Equation (3) for Western and Eastern European countries separately because our analysis in Section 5 showed that these countries behaved differently with respect to the Easterlin Paradox for groups of countries. Furthermore, insignificant dummies for different preceding questions (see Sect. 4) are dropped so as to raise statistical power. We also exclude East Germany (DEE) from the estimation for the EE countries and include DEE in the estimation for the WE countries as bootstrapstrata estimation breaks down in the former estimation when we include DEE. This is probably due to the much longer time series for life satisfaction in DEE as compared to the other EE countries, leading to multicollinearity of trend $\operatorname{lnGDPpc}$ with the (significant) preceding-question dummies. Adding DEE to the estimation for the WE countries does not give problems and hardly affects the estimates for the WE countries.

We start with presenting estimates for Equation (3) for individual countries when choosing $\lambda=$ $\infty$ for trend lnGDPpc and cyclical lnGDPpc. We thus attempt to perform tests of long-term variant EPil of the Easterlin Paradox. However, as explained in Section 1, the hypothesis that the long-term growth rate of GDPpc of an individual country is unrelated to that country's growth rate of happiness is, when controlling for a linear autonomous time trend, untestable. This is due to the perfect collinearity of such a time trend with the long-term growth trend in lnGDPpc. We thus have to drop the interaction terms for either trend $\operatorname{lnGDPpc}$ or year from the regressions. ${ }^{44}$ The resulting coefficients may either be understood as not-for-year-controlled correlations of the long-term growth trend in lnGDPpc with mean life satisfaction in a country (when using trend lnGDPpc) or as the overall linear time trends in mean life satisfaction (which may include the effects of changes in any explanatory variable not explicitly modelled, e.g. social trust ${ }^{45}$, when using year). These coefficients can also generally be understood as representing alternative tests of the individual-country variant EPi0 of the Easterlin Paradox (see Sect. 1). Our approach is therefore close to what Easterlin (1974, 1995, 2005, 2017), Layard et al. (2010), Veenhoven (2011), and Clark et al. (2014) did for the case of the USA and other developed countries (see Sect. 2). However, contrary to these studies, our controls for cyclical lnGDPpc, the precedingquestion dummies, and lagged life satisfaction remove possible sources of biases in the tests of EPi0.

Table 8 presents estimates of the interaction coefficient of lagged life satisfaction and the longrun effects of trend lnGDPpc and year for the set of 14 individual WE countries plus DEE $\left(\mathrm{WE}^{+}\right) .{ }^{46}$ Column (1) shows that the interaction coefficient of lagged life satisfaction is (strongly) significant and large positive for most countries, but for some it is insignificant. Columns (2) and (3) reveal a (marginally) significant and positive long-run effect of trend lnGDPpc or year for eight countries,

\footnotetext{
44 The perfect collinearity of the two variables implies that levels of significance will always be the same for both variables. Moreover, given that the long-term growth rate was positive in all countries considered, this also implies that both variables will always have coefficients of the same sign.

${ }^{45}$ But crucially also including the effect of the long-term growth trend in lnGDPpc.

46 This regression includes only two significant dummies for the preceding questions. The first dummy controls for a question on which political party the respondent supports (in the 1979 and 1983 waves). The second of these dummies concerns a question on the share of friends appreciating talk about politics (in the 1998 wave). These dummies have long-run effects averaged across countries of -0.06 and -0.07 , respectively.
} 
namely Denmark, East Germany, Finland, France, Great Britain, Ireland (one-tailed $p=0.10$ ), Italy, and Sweden. For these countries we therefore have initial evidence for a rejection of EPi0. In contrast, Austria, Greece, and Portugal show a significant negative effect, and we do not find significant effects for Belgium, the Netherlands, Spain, and West Germany. However, just as the results in the previous sections, some of these effects may be driven by the recent economic crisis. Robustness estimations for the period prior to 2008 (see Table B.4 in Appendix B) reveal that our rejection of EPi0 is not robust to this restriction for East Germany, where we now obtain strongly insignificant long-run effects. However, we also fail to corroborate our confirmation of EPi0 for Spain, where we now find significant positive effects. We therefore obtain robust evidence for a rejection of EPi0 for Denmark, Finland, France, Great Britain, Ireland, Italy, and Sweden.

\section{Insert Table 8}

Moving on to the group of Eastern European countries, we note - as was the case in Section 5.1 - that the estimation period of 11 years is too short for medium-term cycles to be filtered out. As a consequence, the present results can better be interpreted as a test of a weaker, not-for-year-controlled variant of EPim for the medium term. Moreover, given this short observation window, we replaced the country-specific terms for cyclical lnGDPpc and lagged life satisfaction by common terms across all countries. Table 9 shows (marginally) significant and positive long-run effects of trend lnGDPpc for Bulgaria $(p=0.08)$, Hungary (one-tailed $p=0.08)$, Lithuania, Latvia, Poland (one-tailed $p=0.06$ ), and Romania (one-tailed $\mathrm{p}=0.06$ ). Remarkably, for Slovenia and Turkey we obtain negative (albeit insignificant) long-run coefficients.

\section{Insert Table 9}

However, a limitation of all these estimates of country-specific correlations of mean happiness with long-term economic growth is that they are not controlling for country-specific correlations of mean happiness with an autonomous time trend. To relieve this limitation we test medium-term variant EPim of the Easterlin Paradox for individual countries in the next section.

\subsection{Medium-term variant of the Easterlin Paradox}

In this section we present the results of testing the medium-term variant EPim of the Easterlin Paradox for individual countries. First, we estimate Equation (3) for the group of 14 WE countries plus DEE $\left(\mathrm{WE}^{+}\right)$. Column (1) of Table 10 presents the long-run effects of trend lnGDPpc and cyclical lnGDPpc for all individual $\mathrm{WE}^{+}$countries. The long-run effect of trend lnGDPpc is (marginally) significant and positive for Greece (1.14), Ireland (0.26; $\mathrm{p}=0.07)$, Italy (1.49), and Spain (0.86) in a two-tailed test, and marginally significant and positive for Portugal $(0.58)$ only in a one-tailed test $(\mathrm{p}=0.10)$. 
Interestingly, these are precisely the countries that suffered most from the recent Eurocrisis ${ }^{47}$ Thus, for these countries the medium-term variant EPim of the Easterlin Paradox for individual countries is violated. Note that the positive long-run effects of trend lnGDPpc for these countries go together with (marginally) significant negative time trends. For the other ten countries the long-run effect of trend lnGDPpc is either insignificant or (marginally) significantly negative (for Austria, -1.16; East Germany, -2.27; Great Britain, -0.59 ; the Netherlands, -0.45 , one-tailed $p=0.09$ ). Thus, for these individual countries the medium-term variant EPim of the Easterlin Paradox is confirmed.

\section{Insert Table 10}

However, for countries with 34 or less observations (Austria, East Germany, Finland, Greece, Portugal, Spain, and Sweden) the number of observations may be too low to lead to stable, and hence reliable, estimates of the four interaction terms for each country in Equation (3) (see Sect. 3.2). Therefore, column (2) of Table 8 presents estimates from a robustness regression of Equation (3) in which the interaction terms for cyclical lnGDPpc have been replaced by their main effects. These estimates are similar to those in column (1), but the long-run effect of trend lnGDPpc has now become clearly significant for Ireland and insignificant for the Netherlands and Portugal even in a one-tailed $t$ test. Thus, violation of the medium-term variant EPim of the Easterlin Paradox is a robust result for Greece, Ireland, Italy, and Spain, but not for Portugal. Furthermore, significant negativity of the longrun effect of trend lnGDPpc is a robust result for Austria, East Germany, and Great Britain, but not for the Netherlands (although the estimate in column (1) for this country seems the more reliable estimate because of the control for country-specific effects of cyclical lnGDPpc).

Another concern regarding our estimates is that despite of the addition of lagged life satisfaction, there may still be some serial correlation in the error term left for some countries. Serial correlation tests for the regressions of Equation (3) in column (1) and column (2) indeed reveal (almost marginally) significant and strong first-order serial correlation for Greece (positive and greater than one), Spain (positive), and West Germany (negative) for the regression in column (1) and for the same countries plus Denmark (negative) and Ireland (positive, $p=0.11$ ) for the regression in column (2). Furthermore, the tests show (almost marginally) significant second-order serial correlation of the same sign for Greece, Spain, and West Germany in both regressions. For the other countries there is no significant serial correlation in the error term. To reduce the serial correlation for the countries with significant serial correlation we add country-specific interaction terms for one-year-lagged trend $\ln G D P p c_{c t-1}$ together with a main effect of one-year-lagged cyclical $\ln G D P p c_{c t-1}$ to Equation (2) with main instead of interaction effect(s) of cyclical $\ln G D P p c_{c t}$ in column $(2)^{48}$, yielding the estimates in column (3) of Table 8. The coefficients of the interactions of trend $\ln G D P p c_{c t-1}$ (not shown) are (marginally)

\footnotetext{
${ }^{47}$ Further in this section we will test whether these results are driven by the period of that crisis.

${ }^{48} \mathrm{We}$ do not add such terms to the regression in column (1) so as to keep the total number of country-specific interaction terms below five per country, which seems too high in comparison with the at most 40 observations per country in our sample to generate sufficiently stable, and hence reliable estimates (see Sect. 3.2).
} 
significantly negative for Greece, Ireland (one-tailed $p=0.07$ ), Portugal (one-tailed $p=0.08$ ), Spain, and West Germany. In combination with (marginally) significantly positive coefficients of the interactions of trend $\ln G D P p c_{c t}$ for these countries (not shown; $\mathrm{p}=0.05$ for Ireland and 0.09 for Portugal), this implies long-run effects of trend lnGDPpc as given by the relevant formula in Section 3.2 and as shown in column (3) of Table 8. The finding that these long-run effects are smaller than the short-run effects of trend lnGDPpc as given by the coefficients of its interactions, suggests adaptation of life satisfaction to medium-term changes in GDPpc in these countries. ${ }^{49}$ The insignificant negative long-run effect of trend lnGDPpc for West Germany implies that this adaptation is full in that country (cf. Vendrik, 2013), whereas the (marginally) significant positive long-run effects of trend lnGDPpc for Greece, Ireland (one-tailed $\mathrm{p}=0.05$ ), Portugal (one-tailed $\mathrm{p}=0.07$ ), and Spain imply only partial adaptation. In general, the long-run effects of trend lnGDPpc are similar to those in column (2), again implying violation of the medium-term variant EPim of the Easterlin Paradox for Greece, Ireland, Italy, and Spain, but now also marginally for Portugal. A serial correlation test now reveals first-order correlation which is insignificant and less positive or even negative for Greece, Ireland, and Spain, still (strongly) significant and even more negative for Denmark and West Germany, and also marginally ( $\mathrm{p}$ $=0.06$ ) significant and large negative for Great Britain. Thus, adding lagged terms for trend $\ln G D P p c_{c t-1}$ and cyclical $\ln G D P p c_{c t-1}$ to the regression in column (2) of Table 8 only leads to less first-order order serial correlation in the error term for Greece, Ireland, and Spain. ${ }^{50}$

However, for countries with less than 40 observations such as Greece (34) and Spain (29), using four interaction terms per country in the regression of column (3) may render their estimates less reliable (see Sect. 3.2). Therefore, we also conduct a robustness regression in which the interaction terms of lagged life satisfaction in the regression of column (3) have been replaced by their main effect (see Sect. 3.2 for the methodology). The results are presented in column (1) of Table B.4 in Appendix B. They again show a violation of the medium-term variant EPim of the Easterlin Paradox for Greece, Italy, and Spain, and marginally (one-tailed $p=0.09$ ) for Portugal, but not for Ireland (one-tailed $p=0.15$ ). However, for Ireland this result seems due to the deviation of the country-specific coefficient from the uniform coefficient of lagged life satisfaction. For countries with considerably less than 30 observations (Austria, East Germany, Finland, Sweden) column (2) of Table B.5 presents the results of dropping the interactions of lagged trend $\ln G D P p c_{c t-1}$ and the main effect of cyclical $\ln G D P p c_{c t-1}$ in the previous regression, which show little change in the estimates for these countries. Finally, to show the impact of the recent Great Recession on our estimates, we estimate both the regression in column (2) of Table 8 (with main effect of cyclical lnGDPpc) and the regression in column (2) of Table B.5 (with main effect of lagged life satisfaction as well) for the period before 2008. The results in columns (3) and (4) of Table B.5 reveal again a (marginally) significant rejection of the medium-term variant EPim of the Easterlin Paradox for Greece, Ireland $(p=0.06$ and one-tailed $p=0.07$, respectively), Italy, and Spain

\footnotetext{
49 The main effect of lagged cyclical $\ln G D P p c_{c t-1}$ is strongly insignificant implying no adaptation to changes in cyclical $\ln G D P p c_{c t}$.

${ }^{50}$ This also holds for the second-order serial correlation in the error term.
} 
(one-tailed $\mathrm{p}=0.09$ in column (3)), and, surprisingly, in column (3) also for Belgium (one-tailed $\mathrm{p}=$ 0.10; size 5.26!), Portugal, and West Germany (size 1.04). However, in column (4) the long-run effects of trend lnGDPpc for the latter three countries are again strongly insignificant, which suggests overfitting due to multicollinearity of the variables for these countries in column (3). Remarkably, the long-run effects of trend lnGDPpc for Austria, East Germany, and Great Britain, which were (strongly) significantly negative in the baseline estimations of Table 8, are (strongly) insignificant in column (3). However, in column (4) this insignificance result only holds for Austria. Thus, at least for this country the significantly negative long-run effect of trend lnGDPpc for the full period is driven by the Great Recession, and hence not robust.

Overall, we can conclude that violation of the medium-term variant EPim of the Easterlin Paradox is a robust result for Greece, Ireland, Italy, and Spain. However, this violation seems inconsistent with the persistently insignificant results for EPgm for the group of four Southern European countries. This insignificance even obtains if we drop Portugal from this group, so it seems contradictory to the (strong) significance of the results for EPim for Greece, Italy, and Spain, separately. However, as mentioned in Section 5.2, the reason for the insignificance on a group level may be the heterogeneity in the effects of changes in trend lnGDPpc on life satisfaction across the SE countries. Notice that our estimates that test for EPgm in Section 5.2 partially depend on the effects of cross-country differences in over-time changes in lnGDPpc on life satisfaction. From Table 10, column (1), we know that the longrun effect of a rise in medium-term trend $\operatorname{lnGDPpc}$ on life satisfaction is much larger in e.g. Italy than in Spain (1.49 vs. 0.86). However, InGDPpc tended to rise more strongly in Spain than in Italy (see Fig. A.1). Thus, there are likely to be some years in which the change in trend lnGDPpc was larger in Spain than in Italy, but the change in life satisfaction was larger in Italy than in Spain. As a results of this type of cases, our estimate of parameter $\beta$ for trend lnGDPpc in equations (1) and (2) will become less positive for the group of SE countries. This can make the overall long-run effect of medium-term trend lnGDPpc on life satisfaction insignificant despite the positive within-country effects.

Furthermore. a comparison of the estimates in Table 10 with the estimates for EPi0 in Table 8 in the previous section suggests that the positive overall time trends in life satisfaction in Denmark, France, and Great Britain in Table 8 are driven by the long-run effects of year in Table 10, which presumably represent time trends in life satisfaction due to other causes than long-term economic growth. Only for Ireland and Italy the positive overall time trends in Table 8 seem to be driven by (marginally) significant long-run effects of medium-term growth in per capita GDP in Table 10 whereas for Finland and Sweden the estimates in Table 10 are (strongly) insignificant, and hence inconclusive.

For the Eastern European (EE) countries except East Germany, column (1) of Table 11 shows the long-run effects of trend lnGDPpc and year from a regression of Equation (3) with main effects instead of interactions of both cyclical lnGDPpc and lagged life satisfaction. In this regression all dummies for different preceding questions have been dropped because they were jointly insignificant. Strikingly, the long-run effects of trend lnGDPpc are (strongly) insignificant for all EE countries. This is unexpected in view of the marginally significant long-run effect of trend lnGDPpc for the group of 
EE countries without East Germany and Turkey in column (7) of Table 4. Our result may be due to too little variation in medium-term economic growth rates of the EE countries over the short estimation period of 11 years. Therefore, column (2) shows the long-run effects of trend lnGDPpc while controlling for a common time trend instead of country-specific time trends. Now for five out of twelve countries these long-run effects are (marginally) significant and positive, namely for Bulgaria, Lithuania, Latvia $(\mathrm{p}=0.08)$, Poland $(\mathrm{p}=0.06)$, and Romania (one-tailed $\mathrm{p}=0.09)$. This makes sense because these were relatively poor countries (see Table 2 and cf. Proto and Rustichini (2013)). However, the control for a common instead of country-specific time trends makes the results of this test dubious for Latvia and Romania as the marginally significant and positive long-run effects of trend lnGDPpc for these countries in column (2) of Table 11 apparently pick up the positive country-specific long-run time trends found in column (1) (see also the discussion in Sect. 1). For the other three countries Bulgaria, Lithuania, and Poland the country-specific long-run time trends in column (1) are more negative than the common long-run time trend, and hence cannot account for the (marginally) significantly positive long-run effects of (mainly positive changes in) trend lnGDPpc in column (2). Thus, we can conclude that the mediumterm variant EPim of the Easterlin Paradox for individual EE countries is only rejected for Bulgaria, Lithuania, and Poland. For a reliable test of whether this variant of the Easterlin Paradox is rejected for other EE countries as well, longer time series than those currently available in Eurobarometer for these countries are needed.

\section{Insert Table 11}

Finally, a comparison of the estimates in Table 11 with the estimates for EPi0 in Table 9 in the previous section suggests that for Latvia and Romania the positive overall time trends in life satisfaction in Table 9 may be driven by other causes than medium-term economic growth, leaving us with only four EE countries (Bulgaria, Hungary, Lithuania, and Poland) for which the positive overall time trends in life satisfaction may be driven by medium-term growth in per capita GDP. Thus, in general we can conclude that because of the perfect collinearity of average growth trends in lnGDPpc with time trends due to other causes, tests of EPi0 per se tell us little about the presence or absence of effects of long and medium-term economic growth on the development of mean life satisfaction in individual countries.

\section{Conclusions}

The starting point of this study was our argument that reliable tests of the Easterlin Paradox should control for the possibility of spuriousness of the correlation between average happiness and long-term economic growth by means of common or country-specific time trends. This led to a distinction between five variants of the paradox along the two dimensions of groups of countries versus individual countries and the long versus medium-term. We tested the four testable variants of the paradox with Eurobarometer data for 27 European countries by estimating country-panel equations for mean life satisfaction in terms of long- or medium-term trend and cyclical components of per capita GDP. When 
testing variants of the paradox that concern groups of countries, we found a clear and robust confirmation of the long- as well as medium-term versions of the paradox for a group of nine Western and Northern European countries. Moreover, we obtained a non-robust rejection of the medium-term variant of the paradox for a set of eleven Eastern European countries. On the level of individual countries, the Easterlin Paradox for the medium term turned out to clearly hold for the nine Western and Northern European countries, but to be consistently rejected for Spain, Greece, Ireland, and Italy. Thus, in the latter four as opposed to the former nine countries, economic growth was positively associated with the development of life satisfaction in the medium term. In the case of the individual Eastern European countries, this was also found to hold for Bulgaria, Lithuania, and Poland, but for the other EE countries the test results are unreliable, partially due to the limited length of the time series (only 11 years). ${ }^{51}$ Note that our results for individual European countries in the medium term are largely consistent with our findings for the groups of countries to which the individual countries belong. Unfortunately, reliable tests of the Easterlin Paradox for individual countries in the long term were not possible because of perfect collinearity of long-term economic growth trends with linear autonomous time trends in mean life satisfaction.

We thus give a nuanced picture of the empirical validity of the Easterlin Paradox. On the one hand, we show that the paradox is confirmed for Western and Northern European countries, both as a group and individually. On the other hand, our results imply a rejection of the medium-term version of the paradox for three individual Southern European countries and Ireland, and at least suggest a rejection of the paradox for Eastern European countries in the medium term. Because the Western and Northern European countries have a high per capita GDP as compared to that of Southern and Eastern European countries and (initially) Ireland, our results are in line with those of Proto and Rustichini (2013), who find a non-monotonic relation between per capita GDP and life satisfaction over time which is significantly positive for poorer countries and (European) regions, but becomes insignificant for richer countries and regions. Thus, on the one hand and in line with Proto and Rustichini and Veenhoven and Vergunst (2014), but contrary to Easterlin (2017), we have obtained evidence that suggests that, at least in the (less appropriate) medium term, the Easterlin Paradox does not hold for lower-income European countries. On the other hand and in line with Proto and Rustichini (2013) and Easterlin (2017), but contrary to Sacks et al. (2013) and Veenhoven and Vergunst (2014), we have found evidence that strongly suggests that, over the last forty years, economic growth did not raise average life satisfaction in the long and medium term in higher-income European countries. Thus, in response to the title of Easterlin's 2017 paper: although the "blissful paradise" of universal validity of the paradox may have been lost, the paradox itself is not!

\footnotetext{
${ }^{51}$ Note that this limitation also holds for other international data sets for life satisfaction and happiness that have a limited number of observations per country. Examples are the World Values Survey (up to six observations) and the Gallup World Poll (13 observations for 2005-2017).
} 


\section{References}

Angeles, L. (2011), A closer look at the Easterlin Paradox. The Journal of Socio-Economics, 40, 67-73.

Angrist, J. D., \& Pischke, J.-S. (2009). Mostly Harmless Econometrics: An Empiricist's Companion. Princeton University Press, Princeton.

Bartolini, S., Bilancini, E., \& Pugno, M. (2013a). Did the decline in social connections depress Americans' happiness? Social Indicators Research, 110, 1033-1059.

Bartolini, S., Bilancini, E., \& Sarracino, F. (2013b). Predicting the trend of well-being in Germany: How much do comparisons, adaptation and sociability matter? Social Indicators Research, 114(2), 169-191.

Bartolini, S., \& Sarracino, F. (2014). Happy for how long? How social capital and economic growth relate to happiness over time. Ecological Economics, 108(Suppl. C), 242-256.

Beja, E. L. (2014). Income growth and happiness: reassessment of the Easterlin Paradox. International Review of Economics, 61(4), 329-346.

Bruno, G. S. (2005). Approximating the bias of the LSDV estimator for dynamic unbalanced panel data models. Economics Letters, 87(3), 361-366.

Bundesagentur für Arbeit (2017). Arbeitslose und Unterbeschäftigung. Retrieved November 10, 2017, from https://statistik.arbeitsagentur.de/nn_217700/Statischer-Content/Rubriken/Arbeitslose-und-gemeldetesStellenangebot/Arbeitslose/Arbeitslosigkeit-in-Deutschland-seit-1950-Monats-Jahreszahlen.html.

Burns, A. F., \& Mitchell, W. C. (1946). Measuring Business Cycles. National Bureau of Economic Research, New York.

Cameron, A. C., \& Miller, D. L. (2015). A practitioner's guide to cluster-robust inference. The Journal of Human Resources, 50(2), 317-372.

Clark, A.E. (2011). Income and happiness: Getting the debate straight. Applied Research in Quality of Life, 6, $253-$ 263.

Clark, A. E., Flèche S., \& Senik, C. (2014). The great happiness moderation. In Clark, A. E. \& Senik, C. (eds.), Happiness and Economic Growth: Lessons from Developing Countries. Oxford University Press, Oxford, 32-139.

Deaton, A. (2008). Income, health, and well-being around the world: Evidence from the Gallup World Poll. Journal of Economic Perspectives, 22(2), 53-72.

De Neve, J. D., Ward, G. W., Keulenaer, F. D., Landeghem, B. V., Kavetsos, G., \& Norton, M. I. (2018). The asymmetric experience of positive and negative economic growth: Global evidence using subjective well-being data. The Review of Economics and Statistics, 100(2), 362-375.

Destatis (2017a). Bruttoinlandsprodukt, Bruttowertschöpfung in den Ländern. Retrieved July 2, 2017, from https:/www.destatis.de/DE/Publikationen/Thematisch/VolkswirtschaftlicheGesamtrechnungen/VGRder Laender/VGR_LaenderergebnisseBand1.html.

Destatis (2017b). Publikation - Preise - Verbraucherpreisindex für Deutschland - Lange Reihen ab 1948. Retrieved November 10, 2017, from https://www.destatis.de/DE/Publikationen/Thematisch/Preise/ Verbraucherpreise/VerbraucherpreisindexLangeReihen.html.

Diener, E., Inglehart, R., \& Tay, L. (2013a). Theory and validity of life satisfaction scales. Social Indicators Research, 112(3), 497-527.

Diener, E., Tay, L., \& Oishi, S. (2013b). Rising income and the subjective well-being of nations. Journal of Personality and Social Psychology, 104(2), 267.

Easterlin, R. A. (1974). Does economic growth improve the human lot? Some empirical evidence. Nations and Households in Economic Growth, 89, 89-125.

Easterlin, R. A. (1995). Will raising the incomes of all increase the happiness of all? Journal of Economic Behavior \& Organization, 27(1), 35-47.

Easterlin, R. A. (2005). Feeding the illusion of growth and happiness: A reply to Hagerty and Veenhoven. Social Indicators Research, 74(3), 429-443.

Easterlin, R. A. (2009). Lost in transition: Life satisfaction on the road to capitalism. Journal of Economic Behavior \& Organization, 71(2), 130-145.

Easterlin, R. A. (2015). Happiness and economic growth: The evidence. In: Glatzer W., Camfield L., Møller V., \& Rojas M. (eds.), Global Handbook of Quality of Life. International Handbooks of Quality-ofLife. Springer, Dordrecht, 283-299.

Easterlin, R. A. (2017). Paradox lost? Review of Behavioral Economics, 4(4), 311-339. 
Easterlin, R. A., McVey, L. A., Switek, M., Sawangfa, O., \& Zweig, J. S. (2010). The happiness-income paradox revisited. Proceedings of the National Academy of Sciences, 107(52), 22463-22468.

Easterlin, R. A., \& Sawangfa, O. (2010). Happiness and economic growth: Does the cross section predict time trends? Evidence from developing countries. International Differences in Well-Being, 166-216.

Feenstra, R. C., Inklaar, R., \& Timmer, M. P. (2015). The next generation of the Penn World Table. The American Economic Review, 105(10), 3150-3182.

GESIS (2017). Eurobarometer Data Service - Population, countries \& regions. Retrieved July 2, 2017, from http://www.gesis.org/eurobarometer-data-service/survey-series/standard-special-eb/populationcountries-regions/.

Graham, C. \& Pettinato (2002). Happiness and Hardship: Opportunity and Insecurity in New Market Economies. The Brookings Institution Press, Washington.

Gruen, C., \& Klasen, S. (2013). Income, inequality, and subjective well-being: an international and intertemporal perspective using panel data. Jahrbuch Für Wirtschaftsgeschichte / Economic History Yearbook, 54(1), $15-35$.

Hamilton, J.D. (2017). Why you should never use the Hodrick-Prescott filter. Review of Economics and Statistics, Just accepted MS, available online, doi: 10.1162/REST_a_00706, 1-25.

Heske, G. (2009). Volkswirtschaftliche Gesamtrechnung DDR 1950-1989. Daten, Methoden, Vergleiche. Historical Social Research/Historische Sozialforschung, Supplement, 21, 1-356.

Hodrick, R. J., \& Prescott, E. C. (1997). Postwar U.S. business cycles: An empirical investigation. Journal of Money, Credit and Banking, 29(1), 1-16.

IMF (2016). World Economic Outlook Database. Retrieved July 2, 2017, from http://www.imf.org/external/ pubs/ft/weo/2016/02/weodata/index.aspx.

Inman, P. (2016), Irish economy surges $26 \%$ as revised figures take in foreign investment. The Guardian, Business, July 12, 2016. Retrieved June 29, 2017, from https://www.theguardian.com/business/ 2016/ jul/12/irisheconomic-growth-revised-figures-foreign-investment-aircraft.

Layard, R., Mayraz, G., \& Nickell, S. J. (2010). Does relative income matter? Are the critics right? In Diener, E., Helliwell, J., \& Kahneman, D. (eds.), International Differences in Wellbeing. Oxford University Press,Oxford, 139-165.

OECD (2017). Level of GDP per capita and productivity. Retrieved July 2, 2017, from https://stats.oecd.org/ Index.aspx?DataSetCode=PDB_LV\#.

Opfinger, M. (2016). The Easterlin paradox worldwide. Applied Economics Letters, 23(2), 85-88.

Proto, E., \& Rustichini, A. (2013). A reassessment of the relationship between GDP and life satisfaction. PLOS ONE, 8(11), 1-10.

Ravn, M. O., \& Uhlig, H. (2002). On adjusting the Hodrick-Prescott filter for the frequency of observations. The Review of Economics and Statistics, 84(2), 371-376.

Sacks, D. W., Stevenson, B., \& Wolfers, J. (2012). Subjective well-being, income, economic development and growth. in Booth, P. (ed.) ... and the Pursuit of Happiness: Well-Being and the Role of Government, 5997. London, The Institute of Economic Affairs.

Sacks, D. W., Stevenson, B., \& Wolfers, J. (2013). Growth in income and subjective well-being over time. Mimeo.

UNCTAD (2017). Gross domestic product: Total and per capita, current and constant (2005) prices, annual, 1970 2015. Retrieved July 2, 2017, from http://unctadstat.unctad.org/wds/TableViewer/ tableView.aspx?ReportId=96.

Veenhoven, R. (2011). Trend average happiness in nations 1946-2010: How much people like the life they live. Trend Report Average Happiness. World Database of Happiness, Happiness in Nations. Erasmus University, Rotterdam.

Veenhoven, R., \& Hagerty, M. (2006). Rising happiness in nations 1946-2004: A reply to Easterlin. Social Indicators Research, 79(3), 421-436.

Veenhoven, R., \& Vergunst, F. (2014). The Easterlin illusion: economic growth does go with greater happiness. International Journal of Happiness and Development, 1(4), 311-343.

Vendrik, M. C. M. (2013). Adaptation, anticipation and social interaction in happiness: An integrated errorcorrection approach. Journal of Public Economics, 105, 131-149.

Stevenson, B., \& Wolfers, J. (2008). Economic growth and subjective well-being: Reassessing the Easterlin Paradox. Brooking Papers on Economic Activity, 2008(1): 1-87. 
Wikipedia (2016). Business cycle. Accessed November 11, 2016, from https://en.wikipedia.org/wiki/ Business_cycle.

Wooldridge, J. M. (2003). Introductory Econometrics; A Modern Approach (2nd ed.). South-Western Thomson Learning, Mason, Ohio.

World Bank. (2017). World Development Indicators. Retrieved July 2, 2017, from http://databank.worldbank. org $/$ data/reports.aspx? source $=2$. 


\section{Figures}

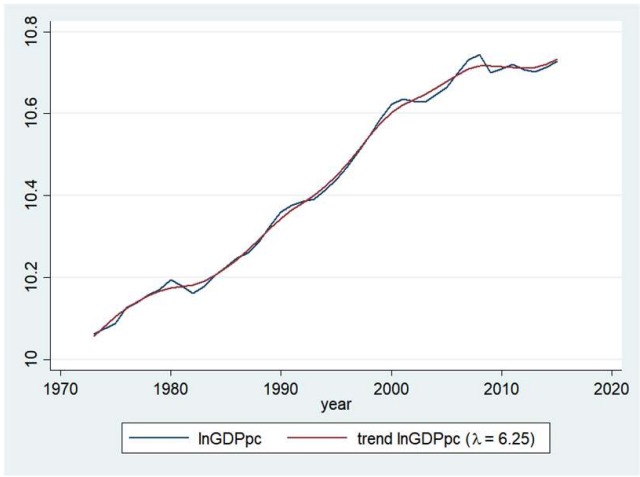

(a)

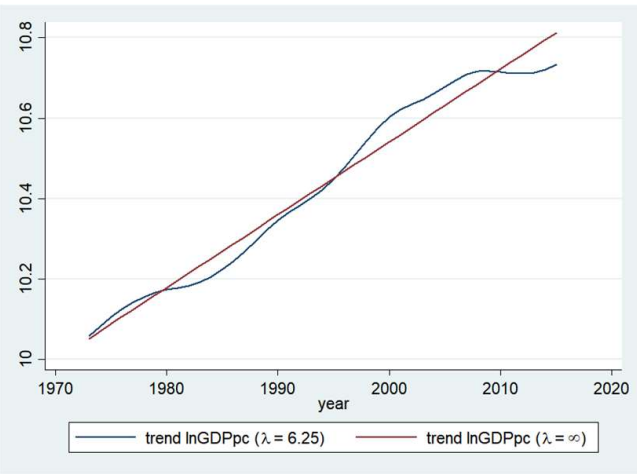

(b)

Figure 1. Time paths for the Netherlands of: (a) $\operatorname{lnGDPpc} v s$. trend $\operatorname{lnGDPpc}$ for $\lambda=6.25$, and (b) trend $\operatorname{lnGDPpc}$ for $\lambda=6.25 v s$. trend $\operatorname{lnGDPpc}$ for $\lambda=\infty$.

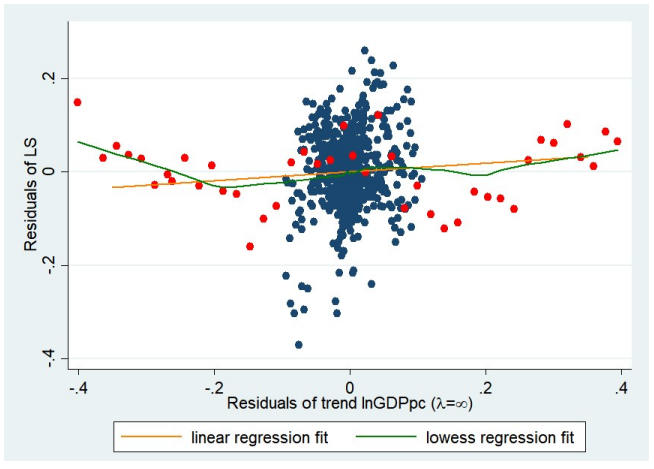

(a)

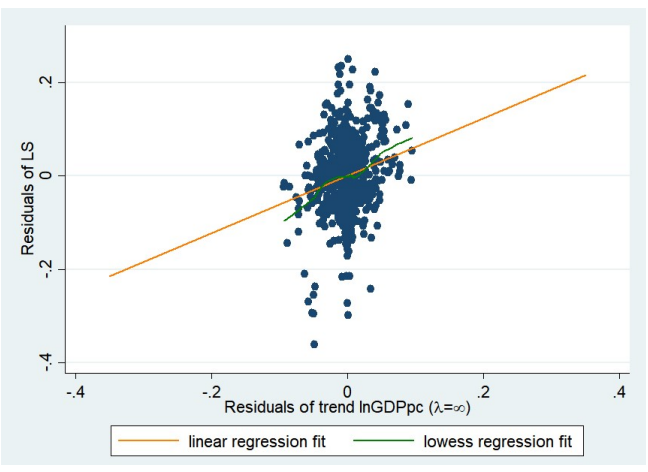

(b)

Figure 2. Scatterplots of residuals of regression of Equation (1) for the long term without trend $\ln G D P p c_{c t}$ against residuals of regression of trend $\ln G D P p c_{c t}$ on year and country dummies for all countries with Ireland marked in red (a) and when omitting Ireland (b).

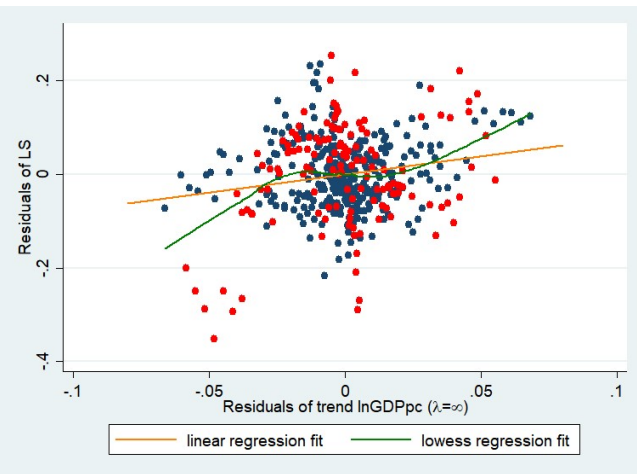

(a)

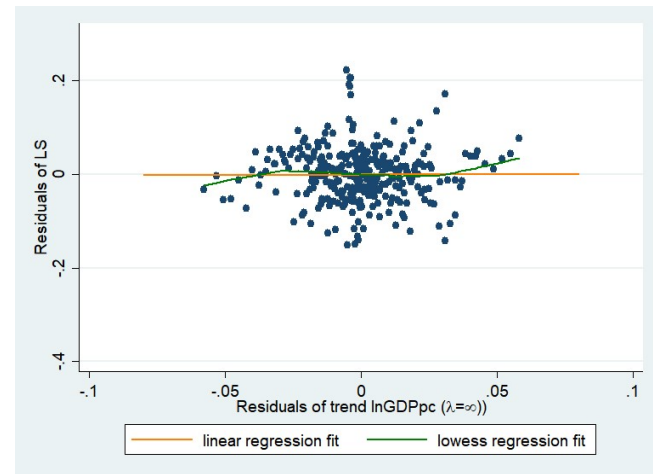

(b)

Figure 3. Scatterplots of residuals of regression of Equation (1) for the long term without trend $\ln G D P p c_{c t}$ against residuals of regression of trend $\ln G D P p c_{c t}$ on year and country dummies for the group of EU-13 countries with Southern European countries marked in red (a) and when omitting Southern European countries (b). 


\section{Tables}

Table 1. Coverage and Descriptive Statistics for Western European Countries

\begin{tabular}{|c|c|c|c|c|c|}
\hline Variable & Country & Mean & SD & Min & Max \\
\hline Austria (AT), T=21 & Life Satisfaction & 3.086 & 0.060 & 2.977 & 3.240 \\
\hline Years Covered: 1995-2015 & GDPpc & 39437 & 3424 & 32708 & 43066 \\
\hline Belgium (BE), $\mathrm{T}=42$ & Life Satisfaction & 3.135 & 0.103 & 2.941 & 3.345 \\
\hline Years Covered: 1973-2015 & GDPpc & 31321 & 6499 & 20499 & 40098 \\
\hline Denmark (DK), $\mathrm{T}=42$ & Life Satisfaction & 3.578 & 0.071 & 3.420 & 3.721 \\
\hline Years Covered: 1973-2015 & GDPpc & 35127 & 6839 & 23442 & 44407 \\
\hline Finland $(\mathrm{FI}), \mathrm{T}=21$ & Life Satisfaction & 3.213 & 0.072 & 3.099 & 3.322 \\
\hline Years Covered: 1995-2015 & GDPpc & 35464 & 4205 & 26540 & 40945 \\
\hline France (FR), $\mathrm{T}=42$ & Life Satisfaction & 2.868 & 0.088 & 2.710 & 3.010 \\
\hline Years Covered: 1973-2015 & GDPpc & 29986 & 5402 & 20239 & 36796 \\
\hline Great Britain (GB), $\mathrm{T}=42$ & Life Satisfaction & 3.185 & 0.067 & 3.065 & 3.376 \\
\hline Years Covered: 1973-2015 & GDPpc & 28916 & 6876 & 18318 & 38609 \\
\hline Greece (GR), $\mathrm{T}=35$ & Life Satisfaction & 2.552 & 0.200 & 2.016 & 2.791 \\
\hline Years Covered: 1981-2015 & GDPpc & 24067 & 4135 & 19233 & 32359 \\
\hline Ireland (IE), $\mathrm{T}=42$ & Life Satisfaction & 3.197 & 0.087 & 3.001 & 3.422 \\
\hline Years Covered: 1973-2015 & GDPpc & 29096 & 13245 & 12264 & 49983 \\
\hline Italy (IT), $\mathrm{T}=42$ & Life Satisfaction & 2.751 & 0.126 & 2.504 & 2.956 \\
\hline Years Covered: 1973-2015 & GDPpc & 29885 & 5359 & 19005 & 36807 \\
\hline Netherlands (NL), T=42 & Life Satisfaction & 3.383 & 0.055 & 3.250 & 3.470 \\
\hline Years Covered: 1973-2015 & GDPpc & 35066 & 7841 & 23439 & 46373 \\
\hline Portugal $(\mathrm{PT}), \mathrm{T}=31$ & Life Satisfaction & 2.535 & 0.160 & 2.110 & 2.768 \\
\hline Years Covered: 1985-2015 & GDPpc & 23343 & 3693 & 14953 & 27291 \\
\hline Spain (ES), $\mathrm{T}=31$ & Life Satisfaction & 2.946 & 0.098 & 2.781 & 3.127 \\
\hline Years Covered: 1985-2015 & GDPpc & 27978 & 4696 & 18971 & 34182 \\
\hline Sweden (SE), T=21 & Life Satisfaction & 3.386 & 0.061 & 3.286 & 3.450 \\
\hline Years Covered: 1995-2015 & GDPpc & 38468 & 4470 & 30218 & 44231 \\
\hline West Germany (DEW), T=42 & Life Satisfaction & 3.047 & 0.081 & 2.836 & 3.200 \\
\hline Years Covered: 1973-2015 & GDPpc & 35328 & 6611 & 23427 & 45396 \\
\hline
\end{tabular}

Note: The life satisfaction statistics hold for the "EB-Restricted" set of waves. 
Table 2. Coverage and Descriptive Statistics for Eastern European Countries

\begin{tabular}{|c|c|c|c|c|c|}
\hline Variable & Country & Mean & SD & Min & Max \\
\hline Bulgaria $(\mathrm{BG}), \mathrm{T}=12$ & Life Satisfaction & 2.177 & 0.097 & 2.041 & 2.379 \\
\hline Years Covered: 2004-2015 & GDPpc & 14932 & 1600 & 11623 & 16956 \\
\hline Czech Republic (CZ), T=12 & Life Satisfaction & 2.900 & 0.050 & 2.816 & 3.005 \\
\hline Years Covered: 2004-2015 & GDPpc & 26803 & 1593 & 23144 & 29079 \\
\hline Croatia (HR), $\mathrm{T}=12$ & Life Satisfaction & 2.789 & 0.045 & 2.723 & 2.893 \\
\hline Years Covered: 2004-2015 & GDPpc & 20270 & 829 & 18656 & 21873 \\
\hline East Germany (DEE), $\mathrm{T}=26$ & Life Satisfaction & 2.799 & 0.114 & 2.602 & 3.053 \\
\hline Years Covered: 1990-2015 & GDPpc & 26691 & 4201 & 17390 & 32835 \\
\hline Estonia (EE), $\mathrm{T}=12$ & Life Satisfaction & 2.764 & 0.052 & 2.692 & 2.843 \\
\hline Years Covered: 2004-2015 & GDPpc & 23003 & 2059 & 19194 & 25410 \\
\hline Hungary (HU), $\mathrm{T}=12$ & Life Satisfaction & 2.430 & 0.105 & 2.304 & 2.653 \\
\hline Years Covered: 2004-2015 & GDPpc & 22241 & 919 & 20683 & 24090 \\
\hline Latvia (LV), $\mathrm{T}=12$ & Life Satisfaction & 2.632 & 0.103 & 2.475 & 2.822 \\
\hline Years Covered: 2004-2015 & GDPpc & 19130 & 2108 & 14929 & 22015 \\
\hline Lithuania (LT), $\mathrm{T}=12$ & Life Satisfaction & 2.628 & 0.107 & 2.507 & 2.861 \\
\hline Years Covered: 2004-2015 & GDPpc & 21338 & 2927 & 16129 & 25711 \\
\hline Poland (PL), $\mathrm{T}=12$ & Life Satisfaction & 2.839 & 0.057 & 2.740 & 2.939 \\
\hline Years Covered: 2004-2015 & GDPpc & 20174 & 2598 & 15932 & 23998 \\
\hline Romania (RO), $\mathrm{T}=12$ & Life Satisfaction & 2.391 & 0.111 & 2.169 & 2.620 \\
\hline Years Covered: 2004-2015 & GDPpc & 17213 & 1900 & 13619 & 19926 \\
\hline Slovakia (SK), T=12 & Life Satisfaction & 2.728 & 0.093 & 2.535 & 2.860 \\
\hline Years Covered: 2004-2015 & GDPpc & 23819 & 2860 & 18294 & 27617 \\
\hline Slovenia (SI), $\mathrm{T}=12$ & Life Satisfaction & 3.068 & 0.046 & 3.003 & 3.151 \\
\hline Years Covered: 2004-2015 & GDPpc & 27410 & 1301 & 24990 & 29966 \\
\hline Turkey (TR), T=12 & Life Satisfaction & 2.756 & 0.108 & 2.588 & 2.932 \\
\hline Years Covered: 2004-2015 & GDPpc & 16287 & 1570 & 13609 & 18695 \\
\hline
\end{tabular}

Note: The life satisfaction statistics hold for the "EB-Restricted" set of waves.

Table 3. Baseline Results for Equation (1) for the Long Term

\begin{tabular}{lllllll}
\hline & $(1)$ & $(2)$ & $(3)$ & $(4)$ & $(5)$ & $(6)$ \\
& All & All, no IE & EU-13 & EU-9 & SE & EE \\
\hline Trend LnGDPpc & 0.095 & $0.616^{*}$ & 0.783 & 0.014 & 1.425 & $0.477^{*}$ \\
& $(0.125)$ & $(0.356)$ & $(0.762)$ & $(0.556)$ & $(1.250)$ & $(0.228)$ \\
& & & & & & $0.832^{* *}$ \\
Cyclical LnGDPpc & $0.765^{* * *}$ & $0.782^{* * *}$ & $0.872^{* * *}$ & 0.159 & 0.527 & $(0.275)$ \\
\hline R-squared & $(0.137)$ & $(0.150)$ & $(0.176)$ & $(0.324)$ & $(0.413)$ & 0.938 \\
Number of Countries & 0.943 & 0.945 & 0.931 & 0.934 & 0.885 & 13 \\
Number of Observations & 27 & 26 & 13 & 9 & 4 & 139 \\
\hline
\end{tabular}

Note: Estimated with Stata's 'regress' command. Country and year dummies included. Country-clustered standard errors in parentheses. Significance levels: for two-tailed t test: $+: \mathrm{p}<0.20, *: \mathrm{p}<0.10, * *: \mathrm{p}<0.05, * * *: \mathrm{p}<0.01$; for one-tailed t test: $+: \mathrm{p}<0.10, *: \mathrm{p}<0.05, * *: \mathrm{p}<0.025, * * *: \mathrm{p}<0.005$ 
Table 4. Baseline Results for Equation (2) for the Long Term

\begin{tabular}{llllllll}
\hline & $(1)$ & $(2)$ & $(3)$ & $(4)$ & $(5)$ & $(6)$ & $(7)$ \\
& All & All, no IE & EU-13 & EU-9 & SE & EE & EE-11 \\
\hline L.Life Satisfaction & $0.805^{* * *}$ & $0.806^{* * *}$ & $0.850^{* * *}$ & $0.716^{* * *}$ & $0.795^{* * *}$ & $0.668^{* * *}$ & $0.527^{* * *}$ \\
& $(0.033)$ & $(0.035)$ & $(0.037)$ & $(0.049)$ & $(0.091)$ & $(0.080)$ & $(0.102)$ \\
Trend LnGDPpc & & & & & & & \\
& 0.039 & $0.170+$ & $0.250+$ & -0.092 & 0.484 & 0.097 & $0.225+$ \\
& $(0.045)$ & $(0.111)$ & $(0.184)$ & $(0.173)$ & $(0.511)$ & $(0.171)$ & $(0.162)$ \\
Cyclical LnGDPpc & $0.146^{* *}$ & $0.170^{* *}$ & 0.079 & 0.053 & 0.049 & $0.595^{* *}$ & $0.614^{* *}$ \\
& $(0.060)$ & $(0.068)$ & $(0.098)$ & $(0.111)$ & $(0.205)$ & $(0.211)$ & $(0.216)$ \\
\hline LR effect of & 0.198 & $0.877^{+}$ & $1.665^{+}$ & -0.323 & 2.363 & 0.291 & $0.476^{+}$ \\
Trend LnGDPp & $(0.235)$ & $(0.568)$ & $(1.199)$ & $(0.618)$ & $(2.344)$ & $(0.504)$ & $(0.319)$ \\
& & & & & & & \\
LR effect of & $0.748^{* *}$ & $0.875^{* *}$ & 0.528 & 0.188 & 0.238 & $1.790^{* *}$ & $1.297^{* *}$ \\
Cyclical LnGDPpc & $(0.310)$ & $(0.364)$ & $(0.659)$ & $(0.386)$ & $(1.012)$ & $(0.802)$ & $(0.556)$ \\
\hline Number of Countries & 27 & 26 & 13 & 9 & 4 & 13 & 11 \\
Number of Observations & 631 & 591 & 434 & 300 & 134 & 157 & 121 \\
\hline
\end{tabular}

Note: Estimated with 'xtlsdvc' command, written by Bruno. Country and year dummies included. Bootstrapped (400 replications) standard errors in parentheses. Significance levels: for two-tailed t test: $+: \mathrm{p}<0.20,{ }^{*}: \mathrm{p}<0.10,{ }^{* *}: \mathrm{p}<0.05,{ }^{* * *}$ : $\mathrm{p}<0.01$; for one-tailed t test: $+: \mathrm{p}<0.10, * \mathrm{p}<0.05,{ }^{* *}: \mathrm{p}<0.025,{ }^{* * *}: \mathrm{p}<0.005$. R-squareds are not reported by the 'xtlsdvc' command.

Table 5. Robustness Results for Equation (2) for the Long Term

\begin{tabular}{|c|c|c|c|c|c|c|}
\hline & $\begin{array}{l}\text { (1) } \\
\text { EU-9 wo. } \\
\text { cyclical } \\
\text { lnGDPpc }\end{array}$ & $\begin{array}{l}(2) \\
\text { EU-9 with } \\
\text { UR and IR }\end{array}$ & $\begin{array}{l}(3) \\
\text { EU-9 } \\
\text { pre-2008 }\end{array}$ & $\begin{array}{l}(4) \\
\text { SE } \\
\text { pre-2008 }\end{array}$ & $\begin{array}{l}(5) \\
\text { EE-11 wo. } \\
\text { cyclical } \\
\text { lnGDPpc }\end{array}$ & $\begin{array}{l}6) \\
\text { EE-11 with } \\
\text { UR and IR }\end{array}$ \\
\hline $\begin{array}{l}\text { LR effect of } \\
\text { Trend LnGDPpc }\end{array}$ & $\begin{array}{l}-0.313 \\
(0.604)\end{array}$ & $\begin{array}{l}-0.569 \\
(0.597)\end{array}$ & $\begin{array}{l}-0.096 \\
(0.694)\end{array}$ & $\begin{array}{l}-0.474 \\
(1.653)\end{array}$ & $\begin{array}{l}0.476 \\
(0.431)\end{array}$ & $\begin{array}{l}0.385 \\
(0.322)\end{array}$ \\
\hline $\begin{array}{l}\text { LR effect of } \\
\text { Cyclical LnGDPpc }\end{array}$ & & $\begin{array}{l}0.127 \\
(0.413)\end{array}$ & $\begin{array}{l}0.087 \\
(0.705)\end{array}$ & $\begin{array}{l}1.099 \\
(0.801)\end{array}$ & & $\begin{array}{l}1.406^{* *} \\
(0.66)\end{array}$ \\
\hline LR effect of UR & & $\begin{array}{l}-0.721 \\
(0.868)\end{array}$ & & & & $\begin{array}{l}-0.129 \\
(0.778)\end{array}$ \\
\hline LR effect of IR & & $\begin{array}{l}-1.820^{* * *} \\
(0.675)\end{array}$ & & & & $\begin{array}{l}-1.780^{* *} \\
(0.867)\end{array}$ \\
\hline Number of Countries & 9 & 9 & 9 & 4 & 11 & 11 \\
\hline Number of Observations & 300 & 300 & 228 & 102 & 121 & 121 \\
\hline
\end{tabular}

Note: Estimated with 'xtlsdvc' command, written by Bruno. Country and year dummies included. Bootstrapped (400 replications) standard errors in parentheses. Significance levels: for two-tailed $\mathrm{t}$ test: + : $\mathrm{p}<0.20, * \mathrm{p}<0.10, * *$ : $\mathrm{p}<0.05, * * *$. $\mathrm{p}<0.01$; for one-tailed t test: $+: \mathrm{p}<0.10,{ }^{*}: \mathrm{p}<0.05,{ }^{* *}: \mathrm{p}<0.025,{ }^{* * *}$ : $\mathrm{p}<0.005$. R-squareds are not reported by the 'xtlsdvc' command. 
Table 6. Baseline Results for Equation (1) for the Medium Term

\begin{tabular}{llllllll}
\hline & $(1)$ & $(2)$ & $(3)$ & $(4)$ & $(5)$ & $(6)$ & $(7)$ \\
& All & All, no IE & EU-13 & EU-9 & SE & EE & EE-11 \\
\hline Trend LnGDPpc & $0.287^{+}$ & $0.729^{* * *}$ & $0.864^{* * *}$ & 0.087 & 0.645 & $0.509^{* *}$ & $0.604^{* *}$ \\
& $(0.184)$ & $(0.198)$ & $(0.274)$ & $(0.273)$ & $(0.521)$ & $(0.202)$ & $(0.192)$ \\
Cyclical LnGDPpc & & & & & & & \\
& $\left(0.933^{* * *}\right.$ & $0.728^{* * *}$ & $0.693^{*}$ & 0.365 & $1.333^{+}$ & $0.931^{* *}$ & $0.781^{*}$ \\
& $(0.152)$ & $(0.164)$ & $(0.323)$ & $(0.324)$ & $(0.708)$ & $(0.416)$ & $(0.399)$ \\
\hline R-squared & 0.938 & 0.945 & 0.931 & 0.934 & 0.882 & 0.938 & 0.965 \\
Number of Countries & 27 & 26 & 13 & 9 & 4 & 13 & 11 \\
Number of Observations & 666 & 624 & 454 & 315 & 139 & 170 & 132
\end{tabular}

Note: Estimated with Stata's 'regress' command. Country and year dummies included. Country clustered standard errors in parentheses. Significance levels: for two-tailed t test: $+: \mathrm{p}<0.20, *: \mathrm{p}<0.10, * *: \mathrm{p}<0.05, * * *: \mathrm{p}<0.01$; for one-tailed $\mathrm{t}$ test: $+: \mathrm{p}<0.10, *: \mathrm{p}<0.05, * *: \mathrm{p}<0.025, * * *: \mathrm{p}<0.005$.

Table 7. Baseline Results for Equation (2) for the Medium Term

\begin{tabular}{|c|c|c|c|c|c|c|c|}
\hline & (1) & (2) & (3) & (4) & (5) & (6) & (7) \\
\hline & All & All, no IE & EU-13 & EU-9 & SE & $\mathrm{EE}$ & EE-11 \\
\hline LR effect of & $0.315^{+}$ & $0.766^{* *}$ & $0.931^{+}$ & -0.029 & 0.603 & 0.282 & $0.562^{*}$ \\
\hline Trend LnGDPpc & $(0.208)$ & $(0.311)$ & $(0.590)$ & $(0.359)$ & $(0.882)$ & $(0.476)$ & $(0.340)$ \\
\hline LR effect of & $2.272^{* *}$ & $1.804^{*}$ & -1.379 & -0.461 & 0.844 & $1.989^{*}$ & $1.414^{*}$ \\
\hline Cyclical LnGDPpc & $(0.943)$ & $(0.941)$ & $(2.341)$ & $(1.334)$ & $(4.152)$ & $(1.050)$ & $(0.835)$ \\
\hline Number of Countries & 27 & 26 & 13 & 9 & 4 & 13 & 11 \\
\hline $\begin{array}{l}\text { Number of } \\
\text { Observations }\end{array}$ & 631 & 591 & 434 & 300 & 134 & 157 & 121 \\
\hline
\end{tabular}


Table 8. Baseline Results for Equation (3) for $\mathrm{WE}^{+}$Countries and the Long Term

(1)

\section{L.Life Satisfaction}

\begin{tabular}{l}
\hline \\
\hline Austria $(\mathrm{T}=20)$ \\
Belgium $(\mathrm{T}=40)$ \\
Denmark $(\mathrm{T}=40)$ \\
East Germany $(\mathrm{T}=25)$ \\
Finland $(\mathrm{T}=20)$ \\
France $(\mathrm{T}=40)$
\end{tabular}

Great Britain $(\mathrm{T}=40)$

Greece $(\mathrm{T}=34)$

Ireland $(\mathrm{T}=40)$

Italy $(\mathrm{T}=40)$

Netherlands $(\mathrm{T}=40)$

Portugal $(\mathrm{T}=29)$

Spain ( $\mathrm{T}=29)$

Sweden $(\mathrm{T}=20)$

West Germany $(\mathrm{T}=40)$

Coefficient SE

$-0.047$

$0.699 * * *$

$(0.256)$

$(0.129)$

$0.438 * * \quad(0.193)$

$0.522 * * \quad(0.210)$

$0.475^{* * *} \quad(0.145)$

$0.312^{* *}$

$(0.172)$

$0.424 * *$

$0.311^{* *}$

0.099

$(0.169)$

$(0.166)$

$(0.186)$

$0.557 * * *$

$(0.126)$

0.174

$(0.324)$

$0.466^{* * *}$

$(0.177)$

0.197

$(0.293)$

$0.624 * * * \quad(0.149)$

Number of Observations:
(2)

LR Effect of Trend LnGDPpc on LS

\begin{tabular}{llll} 
Effect & SE & Effect & SE \\
\hline$-0.317^{* *}$ & $(0.142)$ & $-0.004^{* *}$ & $(0.001)$ \\
-0.009 & $(0.185)$ & -0.000 & $(0.003)$
\end{tabular}

$0.004^{* * *} \quad(0.000)$

$0.270^{* * *} \quad(0.042)$

$0.584^{* * *} \quad(0.192)$

$0.514^{* * *} \quad(0.163)$

$0.406^{* * *} \quad(0.074)$

$0.231^{* * *} \quad(0.038)$

$-1.195^{* * *} \quad(0.222)$

$0.043^{+} \quad(0.033)$

$0.195^{* * *} \quad(0.072)$

0.075

$(0.064)$

$-0.836^{* * *} \quad(0.123)$

$(0.123)$
$(0.176)$

$-0.027$

$(0.176)$
$(0.114)$

$0.012^{* * *}$

$0.008^{* * *}$

$(0.003)$

$(0.002)$

$0.006^{* * *} \quad(0.001)$

$0.004^{* * *} \quad(0.000)$

$-0.015^{* * *} \quad(0.002)$

$\begin{array}{ll}0.001^{+} & (0.001) \\ 0.002^{* * *} & (0.001)\end{array}$

$0.001 \quad(0.001)$

$-0.014^{* * *} \quad(0.002)$

$0.457^{* * *}$

$(0.141)$

$-0.000$

$(0.003)$

0.107

497

$0.008^{* * *}$

(0.002)

0.001

(0.002)

Note: Estimated with Stata's 'regress'. The life satisfaction regressions for columns (1)-(3) control for country-specific effects of cyclical lnGDPpc, lagged life satisfaction, and country dummies, and omit country-specific effects of either year (column (2)) or trend lnGDPpc (column (3)). T now indicates the number of effective observations that identifies the interaction coefficient for a particular country (one lower than $\mathrm{T}$ in Table 1). Strata bootstrapped (400 replications) standard errors in parentheses. Significance levels: for two-tailed t test: + : $<<0.20, *: p<0.10,{ }^{*}: \mathrm{p}<0.05, * * *: \mathrm{p}<0.01$; for one-tailed $\mathrm{t}$ test: $+: \mathrm{p}<0.10, *: \mathrm{p}<0.05, * *: \mathrm{p}<0.025, * * *: \mathrm{p}<0.005$

Table 9. Baseline Results for Equation (3) for Eastern European Countries and the Long Term

(1)

LR Effect of Trend LnGDPpc on LS

\begin{tabular}{|c|c|c|c|c|}
\hline & Effect & SE & Effect & SE \\
\hline Bulgaria $(\mathrm{T}=11)$ & $0.881^{*}$ & $(0.505)$ & $0.024^{*}$ & $(0.014)$ \\
\hline Croatia $(\mathrm{T}=11)$ & 3.411 & $(5.378)$ & 0.007 & $(0.012)$ \\
\hline Czech Republic $(\mathrm{T}=11)$ & 0.451 & $(1.007)$ & 0.006 & $(0.013)$ \\
\hline Estonia $(\mathrm{T}=11)$ & 0.549 & $(0.600)$ & 0.008 & $(0.009)$ \\
\hline Hungary $(\mathrm{T}=11)$ & $4.278^{+}$ & $(2.984)$ & $0.029^{+}$ & $(0.020)$ \\
\hline Latvia $(\mathrm{T}=11)$ & $1.149^{* *}$ & $(0.564)$ & $0.026^{* *}$ & $(0.012)$ \\
\hline Lithuania $(\mathrm{T}=11)$ & $0.883^{* * *}$ & $(0.318)$ & $0.030^{* * *}$ & $(0.010)$ \\
\hline Poland $(\mathrm{T}=11)$ & $0.368^{+}$ & $(0.241)$ & $0.013^{+}$ & $(0.008)$ \\
\hline Romania $(\mathrm{T}=11)$ & $1.138^{+}$ & $(0.718)$ & $0.032^{+}$ & $(0.020)$ \\
\hline Slovakia $(\mathrm{T}=11)$ & 0.001 & $(0.350)$ & 0.000 & $(0.011)$ \\
\hline Slovenia $(\mathrm{T}=11)$ & -2.228 & (1.839) & -0.007 & $(0.006)$ \\
\hline Turkey $(\mathrm{T}=11)$ & -0.721 & $(0.898)$ & -0.018 & $(0.022)$ \\
\hline
\end{tabular}

(2)

LR Effect of Year on LS

Note: Estimated with Stata's 'regress'. The life satisfaction regressions for columns (1) and (2) control for main effects of cyclical lnGDPpc and lagged life satisfaction, and country dummies, and omit country-specific effects of either year (column (1)) or trend lnGDPpc (column (2)). T now indicates the number of effective observations that identifies the interaction coefficient for a particular country (one lower than $\mathrm{T}$ in Table 2). Strata bootstrapped (400 replications) standard errors in parentheses. Significance levels: for two-tailed t test: $+: \mathrm{p}<0.20, *: \mathrm{p}<0.10,{ }^{* *}: \mathrm{p}<0.05, * * *: \mathrm{p}<0.01$; for one-tailed t test: $+: \mathrm{p}<0.10, *: \mathrm{p}<0.05, * *: \mathrm{p}<0.025, * * *: \mathrm{p}<0.005$ 
Table10. Baseline Results for Equation (3) for $\mathrm{WE}^{+}$Countries and the Medium Term

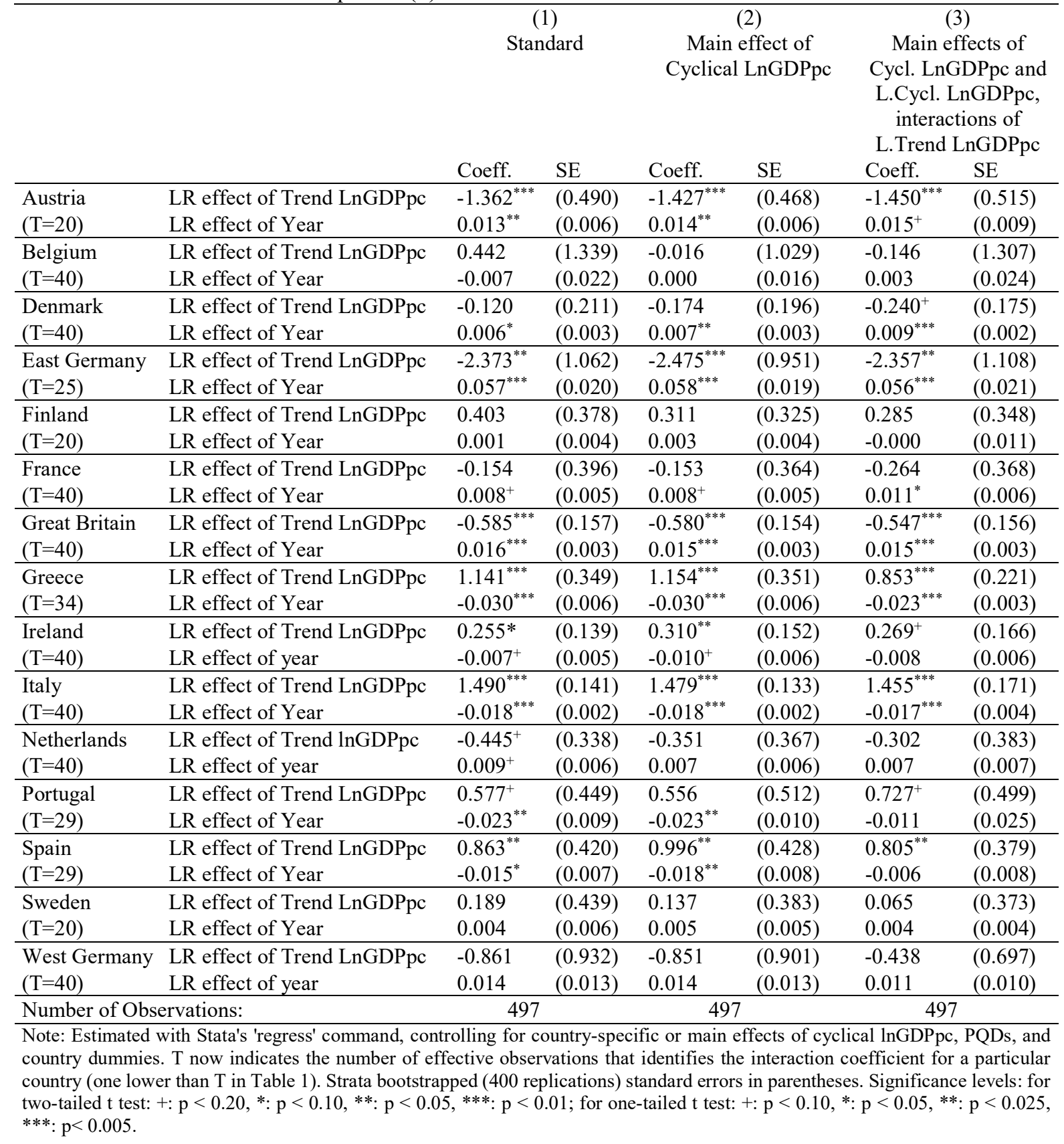


Table 11. Baseline Results for Equation (3) for Eastern European Countries and the Medium Term

\begin{tabular}{|c|c|c|c|c|c|}
\hline & & & & Main e & of Year \\
\hline & & Effect & SE & Effect & SE \\
\hline Bulgaria & LR effect of Trend LnGDPpc & 1.516 & $(2.155)$ & $0.957^{* *}$ & $(0.412)$ \\
\hline$(\mathrm{T}=11)$ & LR effect of Year & -0.018 & $(0.051)$ & -0.003 & $(0.006)$ \\
\hline Croatia & LR effect of Trend LnGDPpc & 1.011 & (2.108) & 1.335 & $(1.708)$ \\
\hline$(\mathrm{T}=11)$ & LR effect of Year & 0.004 & $(0.012)$ & -0.003 & $(0.006)$ \\
\hline Czech Republic & LR effect of Trend LnGDPpc & -1.253 & $(4.130)$ & 0.421 & $(0.993)$ \\
\hline$(\mathrm{T}=11)$ & LR effect of Year & 0.020 & $(0.035)$ & -0.003 & $(0.006)$ \\
\hline Estonia & LR effect of Trend LnGDPpc & 1.787 & $(1.740)$ & 0.828 & $(0.684)$ \\
\hline$(\mathrm{T}=11)$ & LR effect of Year & -0.018 & $(0.029)$ & -0.003 & $(0.006)$ \\
\hline Hungary & LR effect of Trend LnGDPpc & 3.527 & $(3.997)$ & 3.530 & $(2.853)$ \\
\hline$(\mathrm{T}=11)$ & LR effect of Year & -0.000 & $(0.027)$ & -0.003 & $(0.006)$ \\
\hline Latvia & LR effect of Trend LnGDPpc & -0.855 & $(1.531)$ & $1.045^{*}$ & $(0.582)$ \\
\hline$(\mathrm{T}=11)$ & LR effect of Year & $0.042^{+}$ & $(0.032)$ & -0.003 & $(0.006)$ \\
\hline Lithuania & LR effect of Trend LnGDPpc & 1.540 & $(1.931)$ & $0.895^{* * *}$ & $(0.324)$ \\
\hline$(\mathrm{T}=11)$ & LR effect of Year & -0.024 & $(0.063)$ & -0.003 & $(0.006)$ \\
\hline Poland & LR effect of Trend LnGDPpc & 1.037 & $(2.987)$ & $0.434^{*}$ & $(0.244)$ \\
\hline$(\mathrm{T}=11)$ & LR effect of Year & -0.024 & $(0.101)$ & -0.003 & $(0.006)$ \\
\hline Romania & LR effect of Trend LnGDPpc & 0.246 & (3.138) & $0.922^{+}$ & $(0.691)$ \\
\hline$(\mathrm{T}=11)$ & LR effect of Year & 0.019 & $(0.080)$ & -0.003 & $(0.006)$ \\
\hline Slovakia & LR effect of Trend LnGDPpc & 1.124 & $(4.495)$ & 0.220 & $(0.315)$ \\
\hline$(\mathrm{T}=11)$ & LR effect of Year & -0.033 & $(0.116)$ & -0.003 & $(0.006)$ \\
\hline Slovenia & LR effect of Trend LnGDPpc & -0.170 & (1.194) & -0.483 & $(0.979)$ \\
\hline$(\mathrm{T}=11)$ & LR effect of Year & $-0.009^{+}$ & $(0.006)$ & -0.003 & $(0.006)$ \\
\hline Turkey & LR effect of Trend LnGDPpc & 2.823 & $(7.908)$ & -0.595 & $(0.760)$ \\
\hline$(\mathrm{T}=11)$ & LR effect of Year & -0.086 & $(0.201)$ & -0.003 & $(0.006)$ \\
\hline Number of Obse & vations: & & & & \\
\hline $\begin{array}{l}\text { Note: Estimated } \\
\text { country dummies. } \\
\text { particular country } \\
\text { Significance level } \\
*: \mathfrak{p}<0.05, * *: p\end{array}$ & for two-tailed $t$ test: $+: \mathrm{p}<0.20$ & T & 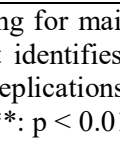 & of cycl & $\begin{array}{l}\text { DPpc and } \\
\text { ient for a } \\
\text { irentheses } \\
: p<0.10\end{array}$ \\
\hline
\end{tabular}




\section{Appendix A. Restrictions of Eurobarometer Data Sets and Country Graphs}

Table A.1. List of Waves and Preceding Questions for EB Standard and EB Restricted

\begin{tabular}{|c|c|c|c|c|c|c|c|}
\hline Wave & Year & Preceding Question & & Wave & Year & Preceding Question & \\
\hline ECS1973 & 1973 & Satisfaction with democracy in [country] & & EB52.0 & 1999 & How often persuade friends & \\
\hline EB3 & 1975 & Satisfaction with work & $\mathrm{X}$ & EB53 & 2000 & How often persuade friends & \\
\hline EB4 & 1975 & How often persuade friends & & EB54.1 & 2000 & How often persuade friends & \\
\hline EB5 & 1976 & How often persuade friends & & EB55.1 & 2001 & How often persuade friends & \\
\hline EB6 & 1976 & Unknown & $\mathrm{X}$ & EB56.1 & 2001 & Problem with high blood pressure & $\mathrm{X}$ \\
\hline EB7 & 1977 & Unknown & & EB56.2 & 2001 & How often persuade friends & \\
\hline EB8 & 1977 & Unknown & & EB57.1 & 2002 & How often persuade friends & \\
\hline EB9 & 1978 & Unknown & & EB44.2 & 1996 & Nationality of respondent & \\
\hline EB10 & 1978 & Unknown & & EB60.1 & 2003 & How often persuade friends & \\
\hline EB11 & 1979 & Support for party in European Parliam. & & EB62.0 & 2004 & How often persuade friends & \\
\hline EB13 & 1980 & Unknown & & EB63.4 & 2005 & How often persuade friends & \\
\hline EB15 & 1981 & Unknown & & EB64.2 & 2005 & How often persuade friends & \\
\hline EB17 & 1982 & Topics of interest & & EB65.2 & 2006 & How often persuade friends & \\
\hline EB18 & 1982 & Type of housing & & EB66.1 & 2006 & How often persuade friends & \\
\hline EB19 & 1983 & Support for party in European Parliam. & & EB67.2 & 2007 & How often persuade friends & \\
\hline EB20 & 1983 & Educational attainment & $\mathrm{X}$ & EB68.1 & 2007 & How often persuade friends & \\
\hline EB21 & 1984 & Place of voter registration & & EB69.2 & 2008 & How often persuade friends & \\
\hline EB22 & 1984 & Opinion on African presidents & $\mathrm{X}$ & EB70.1 & 2008 & How often persuade friends & \\
\hline EB23 & 1985 & Place of voter registration & & EB71.1 & 2009 & Frequency of discussing politics & $\mathrm{X}$ \\
\hline EB24 & 1985 & Change financial satisf. last 12 months & $\mathrm{X}$ & EB71.2 & 2009 & Nationality of respondent & \\
\hline EB25 & 1986 & Place of voter registration & & EB71.3 & 2009 & Nationality of respondent & \\
\hline EB26 & 1986 & Change financial satisf. last 12 months & $\mathrm{X}$ & EB72.4 & 2009 & Nationality of respondent & \\
\hline EB27 & 1987 & Place of voter registration & & EB73.4 & 2010 & Nationality of respondent & \\
\hline EB28 & 1987 & Change financial satisf. last 12 months & $\mathrm{X}$ & EB73.5 & 2010 & Nationality of respondent & \\
\hline EB29 & 1988 & Place of voter registration & & EB74.2 & 2010 & Nationality of respondent & \\
\hline EB31 & 1989 & registration & & EB75.3 & 2011 & Nationality of $\mathrm{r}$ & \\
\hline EB31.A & 1989 & Place of voter registration & & EB75.4 & 2011 & Paternal educational attainment & $\mathrm{X}$ \\
\hline EB32 & 1989 & Next year better or worse & $\mathrm{X}$ & EB76.3 & 2011 & Like more info. on EU topic & $\mathrm{X}$ \\
\hline EB33 & 1989 & Place of voter registration & & EB77.3 & 2012 & Nationality of respondent & \\
\hline EB34.0 & 1990 & Expect. financial satisf. next 12 months & $\mathrm{X}$ & EB77.4 & 2012 & EU help fragile developing countries? & X \\
\hline EB34.1 & 1990 & Place of voter registration & & EB78.1 & 2012 & Nationality of respondent & \\
\hline EB35.0 & 1991 & Place of voter registration & & EB79.3 & 2013 & Nationality of respondent & \\
\hline EB36 & 1991 & Place of voter registration & & EB79.4 & 2013 & Nationality of respondent & \\
\hline EB37.0 & 1992 & Place of voter registration & & EB80.1 & 2013 & y of respondent & \\
\hline EB37.1 & 1992 & Place of voter registration & & EB80.2 & 2013 & Subjective social class of household & $\mathrm{X}$ \\
\hline EB38.0 & 1992 & Place of voter registration & & EB81.2 & 2014 & Nationality of respondent & \\
\hline EB38.1 & 1992 & Place of voter registration & & & 2014 & Nationality of respondent & \\
\hline EB39.0 & 1993 & Place of voter registration & & EB81.5 & 2014 & Nationality of respondent & \\
\hline EB40 & 1993 & Place of voter registration & & & 2014 & Subjective social class of household & $\mathrm{X}$ \\
\hline EB41.0 & 1994 & Nationality of respondent & & EB82.2 & 2014 & Subjective social class of household & $\mathrm{X}$ \\
\hline EB42 & 1994 & Nationality of respondent & & EB82.3 & 2014 & Nationality of respondent & \\
\hline EB43.1 & 1995 & Nationality of respondent & & & 2014 & Subjective social class of household & $\mathrm{X}$ \\
\hline EB47.1 & 1997 & Motivation for training course & & EB83.3 & 2015 & Nationality of respondent & \\
\hline EB49 & 1998 & Share of friends like talk about politics & & EB83.4 & 2015 & Subjective social class of household & $\mathrm{X}$ \\
\hline
\end{tabular}

Note: Waves marked with "X" are not included in EB Restricted. 
Figure A.1. Life Satisfaction and GDP per capita over time in Western European countries, 19732015

\section{Northern European Countries}
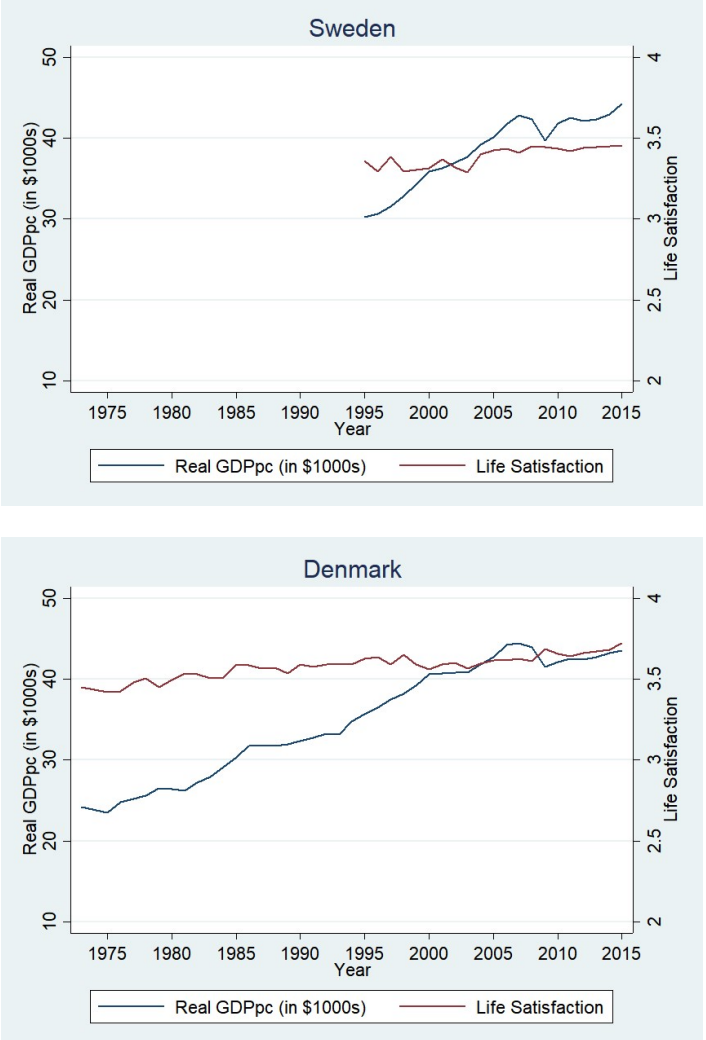

\section{Western European Countries}
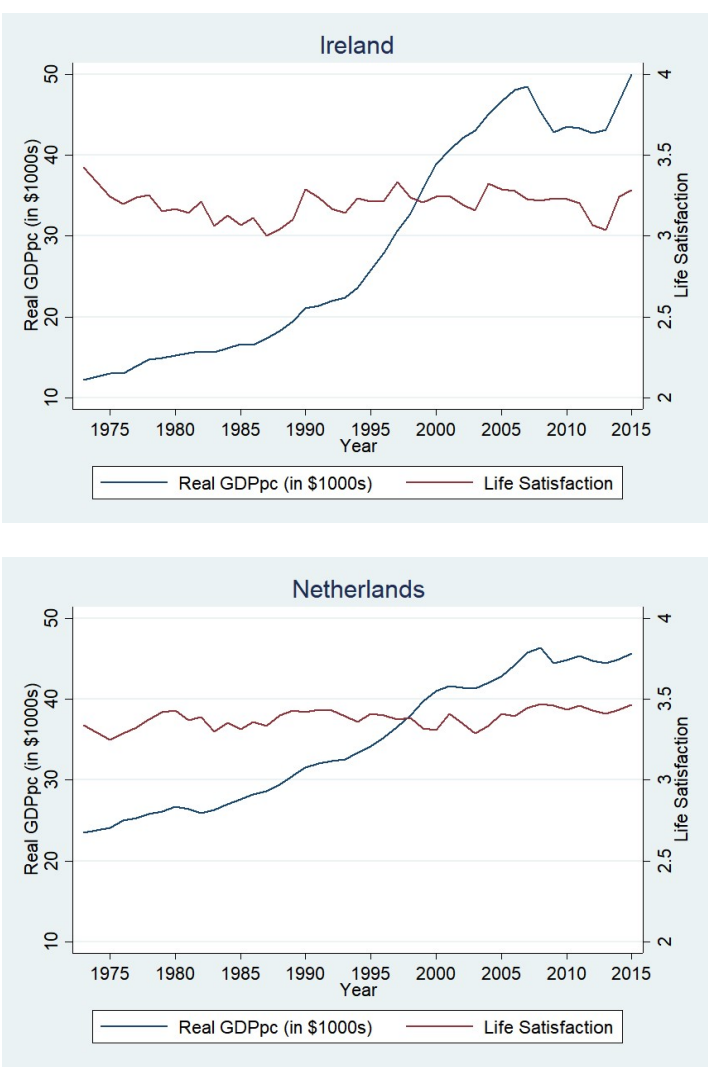
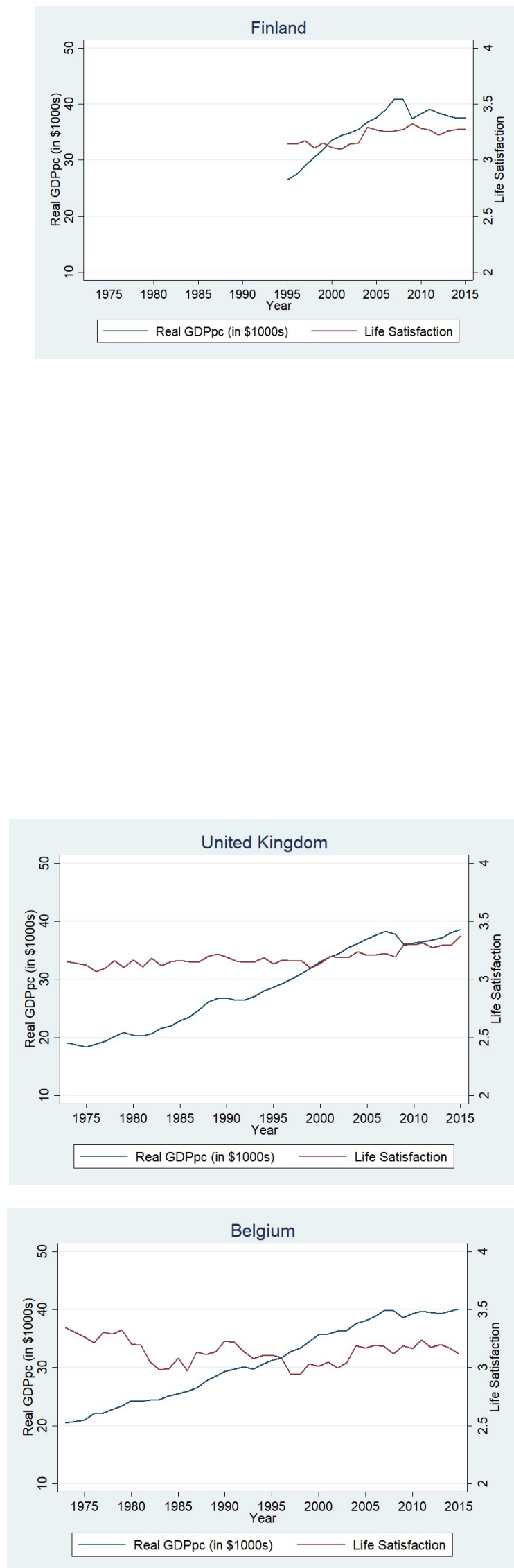


\section{Western European Countries (continued)}
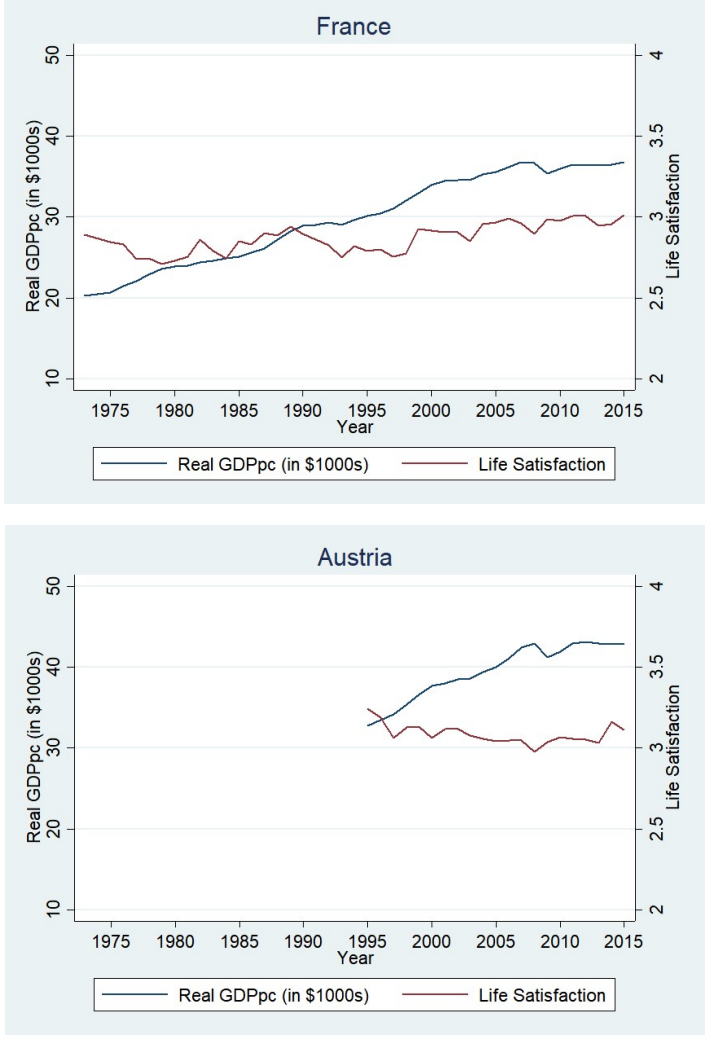

\section{Southern European Countries}
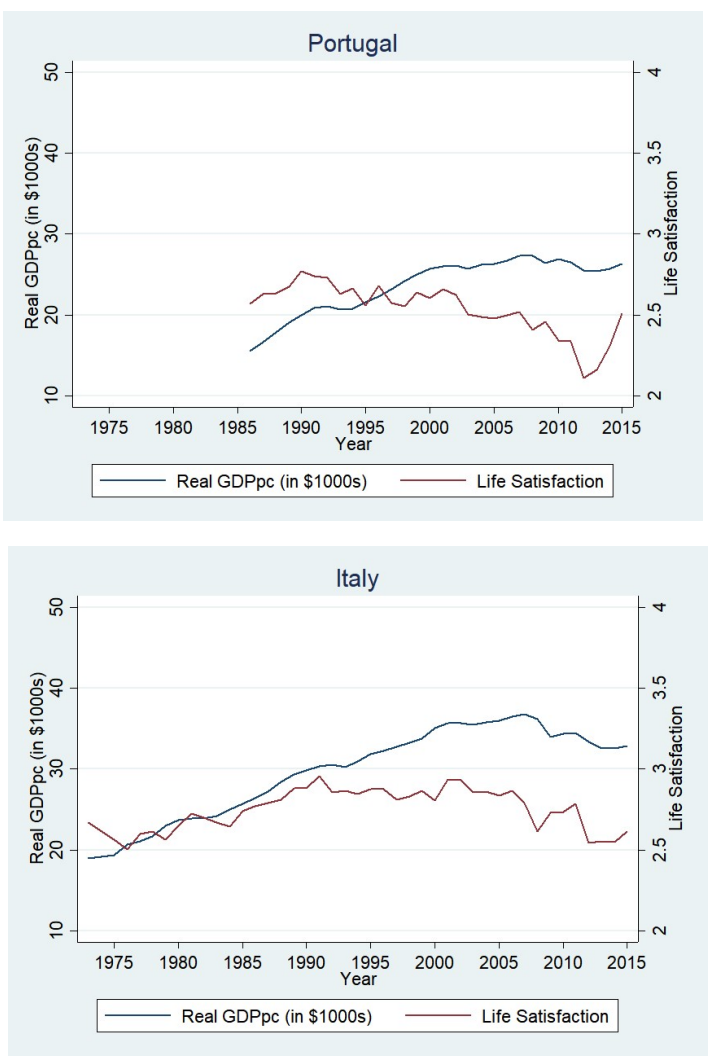
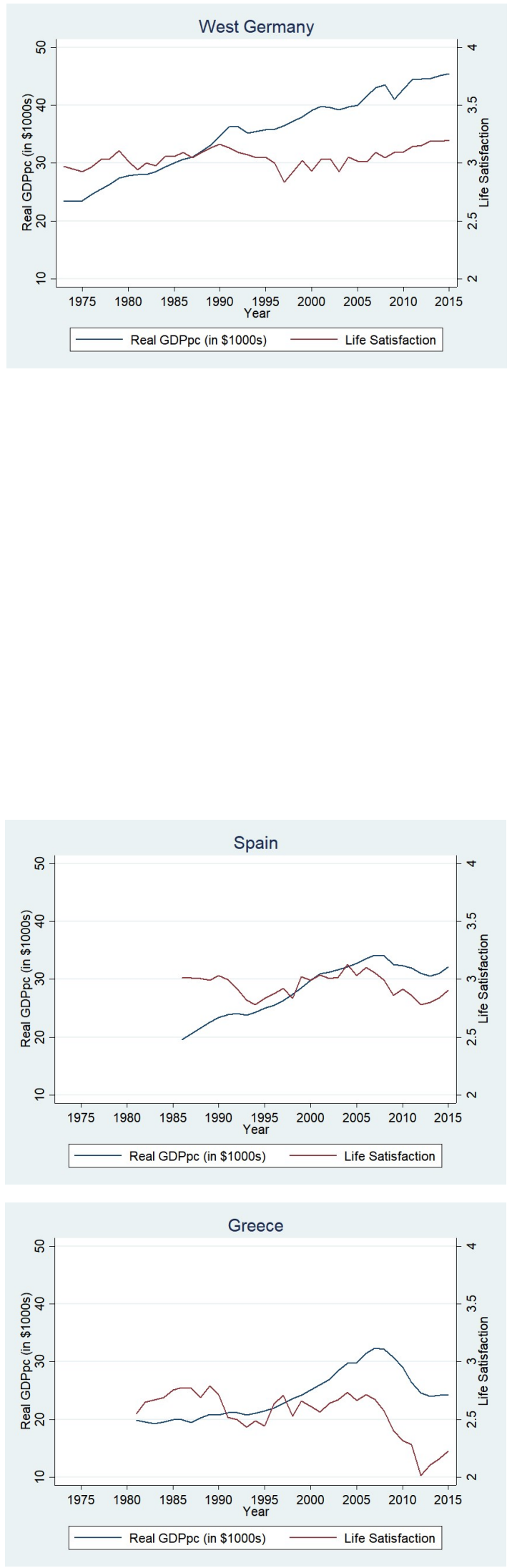


\section{Appendix B. Robustness Results}

Table B.1. Results for Equation (2) for the Long Term when using EB-Restricted

\begin{tabular}{lll}
\hline & $(1)$ & $(2)$ \\
& EU-9 & EE-11 \\
\hline LR effect of & -0.215 & $0.489^{*}$ \\
Trend LnGDPpc & $(0.624)$ & $(0.257)$ \\
& & \\
LR effect of & 0.138 & $0.998^{* *}$ \\
Cyclical LnGDPpc & $(0.391)$ & $(0.413)$ \\
Number of Countries & 9 & 11 \\
Number of Observations & 300 & 121 \\
\hline
\end{tabular}

Note: Estimated with 'xtlsdvc' command, written by Bruno. Country and year dummies included. Bootstrapped (400 replications) standard errors in parentheses. Significance levels: for two-tailed t test: $+: \mathrm{p}<0.20, *: \mathrm{p}<0.10,{ }^{* *}: \mathrm{p}<0.05$, ${ }^{* * *}$ : $\mathrm{p}<0.01$; for one-tailed t test: $+: \mathrm{p}<0.10, *: \mathrm{p}<0.05, * *: \mathrm{p}<0.025, * * * \mathrm{p}<0.005$. R-squareds were not reported by the 'xtlsdvc' command.

Table B.2. Robustness Results for Equation (2) for the Medium Term

\begin{tabular}{|c|c|c|c|c|c|c|c|c|}
\hline & $\begin{array}{l}(1) \\
\text { EU-9 wo. } \\
\text { cyclical } \\
\text { lnGDPpc }\end{array}$ & $\begin{array}{l}(2) \\
\text { EU-9 } \\
\text { with UR } \\
\text { and IR }\end{array}$ & $\begin{array}{l}(3) \\
\text { EU-9 } \\
\text { pre-2008 }\end{array}$ & $\begin{array}{l}\text { (4) } \\
\text { EU-9 } \\
\text { EB- } \\
\text { Restr. }\end{array}$ & $\begin{array}{l}(5) \\
\text { SE } \\
\text { pre-2008 }\end{array}$ & $\begin{array}{l}\text { (6) } \\
\text { EE-11 wo. } \\
\text { cyclical } \\
\text { lnGDPpc }\end{array}$ & $\begin{array}{l}(7) \\
\text { EE-11 } \\
\text { with UR } \\
\text { and IR }\end{array}$ & $\begin{array}{l}\text { (8) } \\
\text { EE-11 } \\
\text { EB- } \\
\text { Restr. }\end{array}$ \\
\hline $\begin{array}{l}\text { LR effect of } \\
\text { Trend LnGDPpc }\end{array}$ & $\begin{array}{l}-0.005 \\
(0.347)\end{array}$ & $\begin{array}{l}-0.177 \\
(0.385)\end{array}$ & $\begin{array}{l}-0.038 \\
(0.516)\end{array}$ & $\begin{array}{l}-0.004 \\
(0.371)\end{array}$ & $\begin{array}{l}0.679 \\
(0.807)\end{array}$ & $\begin{array}{l}0.688^{* *} \\
(0.346)\end{array}$ & $\begin{array}{l}0.400 \\
(0.357)\end{array}$ & $\begin{array}{l}0.550^{* *} \\
(0.268)\end{array}$ \\
\hline $\begin{array}{l}\text { LR effect of } \\
\text { Cyclical LnGDPpc }\end{array}$ & & $\begin{array}{l}-0.481 \\
(1.171)\end{array}$ & $\begin{array}{l}-1.038 \\
(1.520)\end{array}$ & $\begin{array}{l}-0.241 \\
(1.375)\end{array}$ & $\begin{array}{l}4.379 \\
(4.499)\end{array}$ & & $\begin{array}{l}1.579^{+} \\
(1.000)\end{array}$ & $\begin{array}{l}1.020^{+} \\
(0.625)\end{array}$ \\
\hline LR effect of UR & & $\begin{array}{l}-0.803 \\
(0.856)\end{array}$ & & & & & $\begin{array}{l}-0.393 \\
(0.820)\end{array}$ & \\
\hline LR effect of IR & & $\begin{array}{l}-1.727^{* * *} \\
(0.653)\end{array}$ & & & & & $\begin{array}{l}-1.871^{*} \\
(0.983)\end{array}$ & \\
\hline No. of Countries & 9 & 9 & 9 & 9 & 4 & 11 & 11 & 11 \\
\hline No. of Observations & 300 & 300 & 228 & 300 & 102 & 121 & 121 & 121 \\
\hline
\end{tabular}

Note: Estimated with 'xtlsdvc' command, written by Bruno. Country and year dummies included. UR and IR expressed as fractions. Bootstrapped (400 replications) standard errors in parentheses. Significance levels: for two-tailed t test: $+: \mathrm{p}<0.20$, $*: \mathrm{p}<0.10, * *: \mathrm{p}<0.05, * * * \mathrm{p}<0.01$; for one-tailed t test: $+: \mathrm{p}<0.10, *: \mathrm{p}<0.05, * *: \mathrm{p}<0.025, * * * \mathrm{p}<0.005$. R-squareds are not reported by the 'xtlsdvc' command. 
Table B.3 Robustness Results for Equation (3) for $\mathrm{WE}^{+}$countries and the Long Term, Year $<2008$

(1)

LR Effect of Trend LnGDPpc

\begin{tabular}{|c|c|c|c|c|}
\hline & Effect & SE & Effect & SE \\
\hline Austria ( $\mathrm{T}=12)$ & $-0.552^{* *}$ & $(0.215)$ & $-0.011^{* *}$ & $(0.004)$ \\
\hline Belgium $(\mathrm{T}=32)$ & -0.094 & $(0.239)$ & -0.001 & $(0.004)$ \\
\hline East Germany $(\mathrm{T}=17)$ & -0.072 & $(0.108)$ & -0.001 & $(0.002)$ \\
\hline Denmark $(T=32)$ & $0.203^{* * *}$ & $(0.053)$ & $0.003^{* * *}$ & $(0.001)$ \\
\hline Finland $(\mathrm{T}=12)$ & $0.328^{* *}$ & $(0.148)$ & $0.011^{* *}$ & $(0.005)$ \\
\hline France $(\mathrm{T}=32)$ & $0.360^{* * *}$ & $(0.113)$ & $0.006^{* * *}$ & $(0.001)$ \\
\hline Great Britain $(\mathrm{T}=32)$ & $0.097^{* * *}$ & $(0.037)$ & $0.002^{* * *}$ & $(0.000)$ \\
\hline Greece $(\mathrm{T}=26)$ & $-0.194^{+}$ & $(0.134)$ & $-0.003^{+}$ & $(0.002)$ \\
\hline Ireland $(\mathrm{T}=32)$ & $0.065^{* *}$ & $(0.031)$ & $0.002^{* *}$ & $(0.001)$ \\
\hline Italy $(\mathrm{T}=32)$ & $0.552^{* * *}$ & $(0.061)$ & $0.010^{* * *}$ & $(0.001)$ \\
\hline Netherlands $(\mathrm{T}=32)$ & -0.009 & $(0.097)$ & -0.000 & $(0.001)$ \\
\hline Portugal $(\mathrm{T}=21)$ & $-0.270^{* * *}$ & $(0.061)$ & $-0.006^{* * *}$ & $(0.001)$ \\
\hline Spain $(T=21)$ & $0.401^{* *}$ & $(0.195)$ & $0.010^{* *}$ & $(0.005)$ \\
\hline Sweden $(\mathrm{T}=12)$ & $0.320^{*}$ & $(0.194)$ & $0.009^{*}$ & $(0.005)$ \\
\hline West Germany $(\mathrm{T}=32)$ & -0.014 & $(0.078)$ & -0.000 & $(0.001)$ \\
\hline Number of Observations & \multicolumn{2}{|c|}{377} & \multicolumn{2}{|c|}{377} \\
\hline
\end{tabular}

Note: Estimated with Stata's 'regress', controlling for country-specific effects of cyclical lnGDPpc, lagged life satisfaction, and country dummies, and omitting country-specific effects of either year (column (1)) or trend lnGDPpc (column (2)). T now indicates the number of effective observations that identifies the interaction coefficient for a particular country. Strata bootstrapped (400 replications) standard errors in parentheses. Significance levels: for two-tailed t test: $+: \mathrm{p}<0.20, *: \mathrm{p}<0.10$, $* *: \mathrm{p}<0.05, * * *: \mathrm{p}<0.01$; for one-tailed t test: $+: \mathrm{p}<0.10, *: \mathrm{p}<0.05, * *: \mathrm{p}<0.025, * * *: \mathrm{p}<0.005$. 
Table B.4. Robustness Results for Equation (3) for $\mathrm{WE}^{+}$countries and the Medium Term

\begin{tabular}{|c|c|c|c|c|c|c|c|c|c|}
\hline & \multicolumn{2}{|c|}{$\begin{array}{c}(1) \\
\text { Main effects of } \\
\text { Cyclical LnGDPpc, } \\
\text { L.Cyclical LnGDPpc } \\
\text { and L.Life Satisf., } \\
\text { interactions of } \\
\text { L.Trend LnGDPpc }\end{array}$} & \multicolumn{2}{|c|}{$\begin{array}{l}(2) \\
\text { effects of } \\
\text { al LnGDPpc } \\
\text { Life Satisf. }\end{array}$} & \multicolumn{2}{|c|}{$\begin{array}{c}(3) \\
\text { Main effect of } \\
\text { Cyclical LnGDPpc, } \\
\text { pre-2008 }\end{array}$} & \multicolumn{2}{|c|}{$\begin{array}{c}(4) \\
\text { Main effects of } \\
\text { Cyclical LnGDPpc } \\
\text { and L.Life Satisf., } \\
\text { pre-2008 }\end{array}$} \\
\hline & & Effect & SE & Effect & SE & Effect & SE & Effect & SE \\
\hline Austria & LR eff. of Trend LnGDPpc & -1.317 & $(1.565)$ & -1.238 & $(1.381)$ & -0.583 & $(2.470)$ & -1.308 & $(1.168)$ \\
\hline$(\mathrm{T}=20,12)$ & LR eff. of Year & 0.017 & $(0.026)$ & 0.015 & $(0.017)$ & -0.000 & $(0.042)$ & 0.015 & $(0.015)$ \\
\hline $\begin{array}{l}\text { Belgium } \\
(\mathrm{T}=40,32)\end{array}$ & $\begin{array}{l}\text { LR eff. of Trend LnGDPpc } \\
\text { LR eff. of Year }\end{array}$ & $\begin{array}{l}-0.139 \\
0.001 \\
\end{array}$ & $\begin{array}{l}(0.808) \\
(0.015) \\
\end{array}$ & $\begin{array}{l}-0.312 \\
0.004\end{array}$ & $\begin{array}{l}(0.674) \\
(0.010) \\
\end{array}$ & $\begin{array}{l}5.256^{+} \\
-0.103^{+} \\
\end{array}$ & $\begin{array}{l}(4.045) \\
(0.077) \\
\end{array}$ & $\begin{array}{l}-0.450 \\
0.007 \\
\end{array}$ & $\begin{array}{l}(0.601) \\
(0.009) \\
\end{array}$ \\
\hline $\begin{array}{l}\text { East Germany } \\
(\mathrm{T}=25,17)\end{array}$ & $\begin{array}{l}\text { LR eff. of Trend LnGDPpc } \\
\text { LR eff. of Year }\end{array}$ & $\begin{array}{l}-2.388^{+} \\
0.058^{*} \\
\end{array}$ & $\begin{array}{l}(1.774) \\
(0.034) \\
\end{array}$ & $\begin{array}{l}-2.093^{+} \\
0.053^{*}\end{array}$ & $\begin{array}{l}(1.553) \\
(0.030) \\
\end{array}$ & $\begin{array}{l}-0.703 \\
0.012 \\
\end{array}$ & $\begin{array}{l}(0.753) \\
(0.016) \\
\end{array}$ & $\begin{array}{l}-2.744^{* *} \\
0.064^{* *}\end{array}$ & $\begin{array}{l}(1.276) \\
(0.025) \\
\end{array}$ \\
\hline $\begin{array}{l}\text { Denmark } \\
(\mathrm{T}=40,32)\end{array}$ & $\begin{array}{l}\text { LR eff. of Trend LnGDPpc } \\
\text { LR eff. of Year }\end{array}$ & $\begin{array}{l}-0.329^{+} \\
0.010^{* * *}\end{array}$ & $\begin{array}{l}(0.227) \\
(0.003)\end{array}$ & $\begin{array}{l}-0.221 \\
0.007^{*}\end{array}$ & $\begin{array}{l}(0.266) \\
(0.004)\end{array}$ & $\begin{array}{l}0.220 \\
-0.000\end{array}$ & $\begin{array}{l}(0.768) \\
(0.014)\end{array}$ & $\begin{array}{l}-0.209 \\
0.007^{* *}\end{array}$ & $\begin{array}{l}(0.218) \\
(0.003)\end{array}$ \\
\hline $\begin{array}{l}\text { Finland } \\
(\mathrm{T}=20,12)\end{array}$ & $\begin{array}{l}\text { LR eff. of Trend LnGDPpc } \\
\text { LR eff. of Year }\end{array}$ & $\begin{array}{l}0.322 \\
-0.000 \\
\end{array}$ & $\begin{array}{l}(0.379) \\
(0.012) \\
\end{array}$ & $\begin{array}{l}0.363 \\
0.003 \\
\end{array}$ & $\begin{array}{l}(0.368) \\
(0.005) \\
\end{array}$ & $\begin{array}{l}-1.225 \\
0.052 \\
\end{array}$ & $\begin{array}{l}(2.007) \\
(0.066)\end{array}$ & $\begin{array}{l}0.315 \\
0.003 \\
\end{array}$ & $\begin{array}{l}(0.321) \\
(0.005) \\
\end{array}$ \\
\hline $\begin{array}{l}\text { France } \\
(\mathrm{T}=40,32)\end{array}$ & $\begin{array}{l}\text { LR eff. of Trend LnGDPpc } \\
\text { LR eff. of Year }\end{array}$ & $\begin{array}{l}-0.240 \\
0.011^{+}\end{array}$ & $\begin{array}{l}(0.456) \\
(0.007)\end{array}$ & $\begin{array}{l}-0.091 \\
0.007\end{array}$ & $\begin{array}{l}(0.474) \\
(0.006)\end{array}$ & $\begin{array}{l}-0.152 \\
0.008\end{array}$ & $\begin{array}{l}(1.405) \\
(0.023)\end{array}$ & $\begin{array}{l}-0.147 \\
0.008^{+} \\
\end{array}$ & $\begin{array}{l}(0.402) \\
(0.005)\end{array}$ \\
\hline $\begin{array}{l}\text { Great Britain } \\
(\mathrm{T}=40,32)\end{array}$ & $\begin{array}{l}\text { LR eff. of Trend LnGDPpc } \\
\text { LR eff. of Year }\end{array}$ & $\begin{array}{l}-0.643^{* *} \\
0.017^{* * *}\end{array}$ & $\begin{array}{l}(0.286) \\
(0.005)\end{array}$ & $\begin{array}{l}-0.649^{* *} \\
0.017^{* * *}\end{array}$ & $\begin{array}{l}(0.296) \\
(0.005)\end{array}$ & $\begin{array}{l}0.007 \\
0.002\end{array}$ & $\begin{array}{l}(0.412) \\
(0.009)\end{array}$ & $\begin{array}{l}-0.661^{* * *} \\
0.017^{* * *}\end{array}$ & $\begin{array}{l}(0.241) \\
(0.004)\end{array}$ \\
\hline $\begin{array}{l}\text { Greece } \\
(\mathrm{T}=34,26)\end{array}$ & $\begin{array}{l}\text { LR eff. of Trend LnGDPpc } \\
\text { LR eff. of Year }\end{array}$ & $\begin{array}{l}0.677^{* *} \\
-0.021^{* * *}\end{array}$ & $\begin{array}{l}(0.315) \\
(0.005)\end{array}$ & $\begin{array}{l}1.148^{* * *} \\
-0.031^{* * *}\end{array}$ & $\begin{array}{l}(0.420) \\
(0.007)\end{array}$ & $\begin{array}{l}1.266^{* *} \\
-0.028^{* *}\end{array}$ & $\begin{array}{l}(0.606) \\
(0.012)\end{array}$ & $\begin{array}{l}1.137^{* * *} \\
-0.030^{* * *}\end{array}$ & $\begin{array}{l}(0.367) \\
(0.006) \\
\end{array}$ \\
\hline $\begin{array}{l}\text { Ireland } \\
(\mathrm{T}=40,32)\end{array}$ & $\begin{array}{l}\text { LR eff. of Trend LnGDPpc } \\
\text { LR eff. of Year }\end{array}$ & $\begin{array}{l}0.240 \\
-0.006 \\
\end{array}$ & $\begin{array}{l}(0.228) \\
(0.009) \\
\end{array}$ & $\begin{array}{l}0.308^{+} \\
-0.009 \\
\end{array}$ & $\begin{array}{l}(0.220) \\
(0.009) \\
\end{array}$ & $\begin{array}{l}0.374^{*} \\
-0.013^{+} \\
\end{array}$ & $\begin{array}{l}(0.198) \\
(0.008) \\
\end{array}$ & $\begin{array}{l}0.290^{+} \\
-0.009 \\
\end{array}$ & $\begin{array}{l}(0.195) \\
(0.008) \\
\end{array}$ \\
\hline $\begin{array}{l}\text { Italy } \\
(\mathrm{T}=40,32)\end{array}$ & $\begin{array}{l}\text { LR eff. of Trend LnGDPpc } \\
\text { LR eff. of Year }\end{array}$ & $\begin{array}{l}1.368^{* * *} \\
-0.014^{*}\end{array}$ & $\begin{array}{l}(0.354) \\
(0.008)\end{array}$ & $\begin{array}{l}1.498^{* * *} \\
-0.020^{* * *}\end{array}$ & $\begin{array}{l}(0.326) \\
(0.005)\end{array}$ & $\begin{array}{l}2.072^{* * *} \\
-0.029^{* * *}\end{array}$ & $\begin{array}{l}(0.263) \\
(0.005)\end{array}$ & $\begin{array}{l}1.475^{* * *} \\
-0.019^{* * *}\end{array}$ & $\begin{array}{l}(0.272) \\
(0.004) \\
\end{array}$ \\
\hline $\begin{array}{l}\text { Netherlands } \\
(\mathrm{T}=40,32)\end{array}$ & $\begin{array}{l}\text { LR eff. of Trend LnGDPpc } \\
\text { LR eff. of Year }\end{array}$ & $\begin{array}{l}-0.265 \\
0.006 \\
\end{array}$ & $\begin{array}{l}(0.422) \\
(0.007) \\
\end{array}$ & $\begin{array}{l}-0.310 \\
0.007 \\
\end{array}$ & $\begin{array}{l}(0.409) \\
(0.007) \\
\end{array}$ & $\begin{array}{l}-0.227 \\
0.004\end{array}$ & $\begin{array}{l}(0.596) \\
(0.012) \\
\end{array}$ & $\begin{array}{l}-0.352 \\
0.007 \\
\end{array}$ & $\begin{array}{l}(0.351) \\
(0.006) \\
\end{array}$ \\
\hline $\begin{array}{l}\text { Portugal } \\
(\mathrm{T}=29,21)\end{array}$ & $\begin{array}{l}\text { LR eff. of Trend LnGDPpc } \\
\text { LR eff. of Year }\end{array}$ & $\begin{array}{l}0.688^{+} \\
-0.006\end{array}$ & $\begin{array}{l}(0.515) \\
(0.013)\end{array}$ & $\begin{array}{l}0.260 \\
-0.019^{+}\end{array}$ & $\begin{array}{l}(0.604) \\
(0.013)\end{array}$ & $\begin{array}{l}0.939^{* *} \\
-0.031^{* * *}\end{array}$ & $\begin{array}{l}(0.369) \\
(0.009)\end{array}$ & $\begin{array}{l}0.328 \\
-0.020^{*}\end{array}$ & $\begin{array}{l}(0.525) \\
(0.011)\end{array}$ \\
\hline $\begin{array}{l}\text { Spain } \\
(\mathrm{T}=29,21)\end{array}$ & $\begin{array}{l}\text { LR eff. of Trend LnGDPpc } \\
\text { LR eff. of Year }\end{array}$ & $\begin{array}{l}0.841^{* *} \\
-0.007\end{array}$ & $\begin{array}{l}(0.331) \\
(0.006)\end{array}$ & $\begin{array}{l}1.052^{* *} \\
-0.019^{* *}\end{array}$ & $\begin{array}{l}(0.465) \\
(0.009)\end{array}$ & $\begin{array}{l}2.166^{+} \\
-0.045 \\
\end{array}$ & $\begin{array}{l}(1.625) \\
(0.041)\end{array}$ & $\begin{array}{l}1.001^{* *} \\
-0.018^{* *}\end{array}$ & $\begin{array}{l}(0.414) \\
(0.008) \\
\end{array}$ \\
\hline $\begin{array}{l}\text { Sweden } \\
(\mathrm{T}=20,12)\end{array}$ & $\begin{array}{l}\text { LR eff. of Trend LnGDPpc } \\
\text { LR eff. of Year }\end{array}$ & $\begin{array}{l}0.321 \\
0.001\end{array}$ & $\begin{array}{l}(0.700) \\
(0.009)\end{array}$ & $\begin{array}{l}0.408 \\
0.001\end{array}$ & $\begin{array}{l}(0.682) \\
(0.010)\end{array}$ & $\begin{array}{l}-1.353 \\
0.046 \\
\end{array}$ & $\begin{array}{l}(1.973) \\
(0.056)\end{array}$ & $\begin{array}{l}0.294 \\
0.003\end{array}$ & $\begin{array}{l}(0.586) \\
(0.009)\end{array}$ \\
\hline $\begin{array}{l}\text { West Germany } \\
(\mathrm{T}=40,32)\end{array}$ & $\begin{array}{l}\text { LR eff. of Trend LnGDPpc } \\
\text { LR eff. of Year }\end{array}$ & $\begin{array}{l}-0.384 \\
0.011^{+}\end{array}$ & $\begin{array}{l}(0.562) \\
(0.008)\end{array}$ & $\begin{array}{l}-0.620 \\
0.011 \\
\end{array}$ & $\begin{array}{l}(0.626) \\
(0.009)\end{array}$ & $\begin{array}{l}1.028^{* *} \\
-0.018^{* *}\end{array}$ & $\begin{array}{l}(0.451) \\
(0.007)\end{array}$ & $\begin{array}{l}-0.563 \\
0.010 \\
\end{array}$ & $\begin{array}{l}(0.560) \\
(0.008)\end{array}$ \\
\hline Number of Obs & servations: & & & $49^{7}$ & & 37 & & & \\
\hline
\end{tabular}

